\title{
SINGLE REVIEWS
}

Reinventing the Museum: Historical and Contemporary Perspectives on the Paradigm Shift. Gail Anderson, ed. Marburg an der Lahn: Basilisken Press, 2004. 401 pp.

\section{HELAINE SILVERMAN}

University of Illinois

The paradigm shift indicated in the volume's title is the dramatic transformation of museums from collectionsbased, object-displaying, elite institutions to a wide range of visitor-centered museums that are "more socially responsive cultural institution[s] in service to the public" (p. 1). To illustrate this paradigm shift, Gail Anderson has compiled 34 essays, 30 of which were published between 1990-2002. The reinvention of the museum, as the editor terms it, is predicated on change in five key areas, which constitute the organizing framework for the volume: (1) the role of the museum as it struggles to remain relevant; (2) the role of the public as central to the survival of the museum; (3) the evolution of exhibitions and programs as the primary vehicles serving the public; (4) the role of the object in the sense of collections cared for by museums and implicating issues of stewardship and cultural responsibility; and (5) the role of leadership for enabling museums to reach their greatest potential. As explicitly stated by its editor (p. xi), Reinventing the Museum provides an informed basis for discussion and action among staff members, trustees, museum students, and professionals, and a good overview of incisive thinking about museums in recent years. With only four chapters written before 1990, however, it does not "outline the historical evolution and dialogue about the museum" (p. 1) in the 20th century as contended by Anderson, although the inclusion of John Cotton Dana's seminal 1917 article, "The Gloom of the Museum," is a necessary starting point for such an analysis.

Although anthropologists are not the primary audience for the volume, they will find many chapters of interest. One issue of anthropological salience is the treatment of cultural property. Among the several chapters treating aspects of this theme, Karen J. Warren's philosophical perspective is particularly useful. She argues that in addressing cultural property issues we need to consider our conceptual frameworks, the language used in discussions, ways of correcting bias, and alternative models of conflict resolution. She identifies and rejects a dominant Western model for dealing with cultural property, which is characterized by a "near exclusive reliance on a value-hierarchical, value-dualistic, and rights/rules ethic, which subordinates the interests or claims of those in subordinate positions relevant to the dispute" (p. 316). Instead, she proposes an integrative approach that enfranchises overlooked considerations such as different beliefs concerning what constitutes property and ownership in the first place.

Another topic of key interest to anthropologists in several of the chapters is multiculturalism and museums. Amalia Mesa-Bains argues that multiculturalism is "a kind of postcolonial diaspora" (p. 99) in which there are "dual standards of a Western subjectivity and those standards assigned to otherness" (p. 102). Her proposed remedy is to recognize different ways of knowing and being, and to use that cultural awareness to create programs, exhibitions, and education outreach based on "interethnic intimacy-not appropriation, nor co-optation" (p. 108). Edmund Barry Gaither is also concerned with multiculturalism. He rejects "models of American experience that express-directly or indirectlya concept of either/or" (p. 111). Rather, Gaither advocates the position that ethnic, racial, and other communities are part of larger communities, ultimately, the comprehensive U.S. community. Claudine K. Brown's solution to the multiculturalism dilemma is to museologically conceive of all people as belonging to yet more inclusive family, peer group, neighborhood, workplace, and educational communities.

This challenge to serve diverse communities and to raise public participation in museums engenders consideration of the very current issue of museum marketing. I would have liked to see an unpacking of the unproblematized notion of the museum as an industry that appears in Anderson's several introductory essays and other chapters. Several contributions build on this implicit concept to address the competitive marketing of museums in an era of diverse and pervasive entertainment. Neil Kotler and Philip Kotler, a Smithsonian program specialist and a professor of international marketing, respectively, confront this issue headon in their fascinating contribution, "Can Museums Be All Things to All People? Missions, Goals, and Marketing's Role." Robert Janes's "persistent paradoxes" are the conundra of how to make museums broadly popular when they are knowledge based; recognition that even splashy multimedia technology requires people to think to benefit and derive pleasure from the museum visit; and involving the public at a time when museum work is ever-more complex for its staff (among other issues raised).

With its diverse voices and multifaceted relevance to many contemporary museum anthropology problems, Reinventing the Museum should find ready course adoption and is a worthy addition to AltaMira's distinguished list of museum studies publications.

AMERICAN ANTHROPOLOGIST, Vol. 107, Issue 4, pp. 715-750, ISSN 0002-7294, electronic ISSN 1548-1433. (C) 2005 by the American Anthropological Association. All rights reserved. Please direct all requests for permission to photocopy or reproduce article content through the University of California Press's Rights and Permissions website, at http://www.ucpress.edu/journals/rights.htm. 
Black Skins, French Voices: Caribbean Ethnicity and Activism in Urban France. David Beriss. Cambridge, MA: Westview Press, 2004. 156 pp.

\section{RALPH GRILLO}

University of Sussex

This short book by New Orleans anthropologist David Beriss is part of the Westview "Case Studies in Anthropology" series. This is a contemporary version of the long-established and similarly named "Case Studies in Cultural Anthropology," originally published by Holt, Reinhart, and Winston. The latter series was a staple of the undergraduate curriculum and provided many of the ethnographies that students actually read. Like so much of the anthropology of its period, the series tended to have a "tribal" and rural focus: Many of the books were accounts of the Navaho, or the Banyoro, and so on, though other contributions went beyond that conventional remit. The Westview series is also concerned with "particular communities," as its author guidelines put it, but as in much modern anthropology, the studies are not confined to a particular rural or urban locality. Indeed, Beriss's excellent book is a wide-ranging account of transnational migrants from the Caribbean islands of Martinique and Guadeloupe who, over the last forty years in increasing numbers (perhaps a third of the island population), have gone to live and work in France.

The situation of the French Caribbean possessions, whose inhabitants are known collectively as "Antillais," is a peculiar one. Since World War II, they have been administered as overseas departments of France itself, with a status equivalent to those on the mainland. Consequently, Antillais are juridically French citizens and, when in France, viewed as internal migrants with rights. For example, they have access to certain public sector jobs that are denied to other, non-French immigrants. Despite this, their position is ambiguous. They are French juridically, but as Afro-Caribbeans they are by no means accepted as French socially. Despite many decades during which they were subjected to French policies of assimilation-notably through the education system-the culture of Martinique and Guadeloupe, and of Antillais in France, has in many ways remained distinct. They are French, but different. Beriss's book discusses how they (and to some extent the French institutional system) attempt to grapple with, and resolve, the problems this poses.

Much of Beriss's fieldwork dates from 1989 and concerns a series of events and situations he investigated around the time of the Bicentennial celebrations of the French Revolution (he includes an account of what that celebration meant, or did not mean, to Antillais migrants). Later fieldwork in 1998 enabled him assess the significance for Antillais of another grand celebration-the multicultural, multiethnic French soccer team winning the World Cup. The meat of the book, however, is a series of chapters in which he examines debates about "culture" among both French and Antillais (if one may make that distinc- tion), and explores various attempts by different theatrical and religious groups (members of the Catholic Church and Seventh Day Adventists for instance) to ask and answer the question: What does it mean to be Antillais in France?

Antillais themselves, both in the islands and in France, have undertaken various "experiment[s] with alternate ideologies" (p. 129). There are different routes, trajectories and projects, some located in specific historical periods (négritude, créolité), and others emerging through different contemporary institutions. The "Eloge" theater troupe, for example, uses "nostalgia for life in the Antilles to build a sense of identity and community" (p. 87). Another, "Stand-Fast," seeks a place in French society itself, and the middle-class intellectuals and professionals of CEDAGR (Centre d'Entre-aide at d'Etude des Antillais, Guyanais, Réunionnais) strive for the recognition of cultural difference within a broader, indeed global, context of créolité. These projects sit uneasily in contemporary France, with its "republican" model of citizenship and culture emphasizing assimilation into French values, at least in theory. Over the last 25 years there has been a tension between forces pushing for some form of multiculturalism, best seen in practical measures at the local level, and those that reasserted the classic model of the republic, one and indivisible, as most recently in the 2003 Stasi Commission on laicity. The latter seem now to be in the ascendancy, and Beriss's conclusion that "France is being creolized," (p. 133) is overoptimistic, or at least premature.

Overall, this is a rich, well-illustrated book that perhaps needed a little more, a little earlier, on colonial history and the development of the French Caribbean islands in the context of the transatlantic slave trade. Nonetheless it is an exemplary model of its kind that will be enjoyed by students and advanced scholars alike.

Culture on Tour: Ethnographies of Travel. Edward M. Bruner. Chicago: University of Chicago Press, 2005. 308 pp.

\section{MIRIAM KAHN}

University of Washington

Edward Bruner, a seasoned scholar with five decades of ethnographic research behind him as well as one of the most lucid voices in tourism studies, has collected several of his essays (all but one previously published) into a spirited and thoughtful volume, written in remarkably unadorned prose. By approaching tourism from the compounded and intertwined perspectives of ethnographer, tourist, tour leader, and tourism industry employee, Bruner demonstrates that tourism is a system in itself. As an individual who has been both anthropologist and tourist (and occasionally also tour guide), he is perfectly positioned to take such a multifaceted look at tourism.

The nine chapters cover a range of geographical locations, tourism types, and theoretical viewpoints: Maasai tourist productions in Kenya; the historic Elmina Castle in Ghana with its competing narratives; the contested site of 
Abraham Lincoln's New Salem, Illinois; the Israeli fortress of Masada as site of dialogic narrative; Balinese border zones; and the Javanese Taman Mini theme park as site of selfconstruction.

One of Bruner's greatest contributions is his constructivist position, from which he views cultures as continually reinventing themselves. Tourist practices are seen as neither simulacra nor ersatz, but as social performances in their own right. This position allows Bruner to free anthropologists from their previous impasse of thinking along the binary of authenticity-inauthenticity, a persistent focus of tourism scholarship ever since Dean MacCannell's 1970s writing on "staged authenticity." Because culture is always emergent, alive, and in process, every cultural act is authentic. Indeed, what tourists seek is a good show.

Bruner also contributes to discussions about narrative. Because he understands that all players in the tourist drama (tourists, travel agents, locals, etc.) have agency, what interests him is who, in the entangled coproduction, gets to tell which story. He draws the useful distinction between metanarratives (produced and managed by the tourism industry) and tourists' tales (told by tourists). Metanarratives are essential to sell a tourist site. Pretour narratives-those seen in brochures and guidebooks, and on websites-are the "voice-over" that rouse tourists' desires. Yet, once they are on tour, tourists seek experiences that they can turn into narratives of their own, aided in their telling by the show-and-tell mnemonics of postcards, snapshots, videos, and souvenirs.

Several chapters are particularly successful in bolstering Bruner's ideas. Chapter 2, "The Maasai and the Lion King," explores the general complexity of tourism by examining three examples within one country (Kenya), thus freeing scholarship from working within the monolithic commercial versions of their sites. The examples are Mayers Ranch, a reenacted colonial setting designed for foreign tourists, where the Maasai are portrayed as timeless and ahistorical; Bomas, a postindependence ethnic theme park for domestic tourists, which highlights tribal dances and national pride; and Sundowner, where wealthy U.S. citizens and Europeans on safari view Maasai dancers remade in postmodern images of Hollywood pop culture.

Chapter 3, "Slavery and the Return of the Black Diaspora," explores competing narratives at Elmina Castle in Ghana, once a staging area for the Atlantic slave trade. Although African Americans mainly visit the castle to connect to their ancestral past and "return home," Ghanaians visit the site because it glorifies their history. By exploring ironies, such as how Ghanaians see African American tourists as "white" and "foreign," Bruner probes issues of narrative authority-who owns the story and who gets to tell it-and concludes that the main narratives are ultimately bound up in the essential nature of tourism as an economic industry.

Chapter 7, "The Balinese Borderzone," champions Bruner's ideas about the porous boundaries of tourist borderzones. Within these zones, where tourists and perform- ing locals interact, each group comes to the setting with different goals and expectations. Bruner provides a marvelous example of blurred boundaries between researcher, tour guide, tourist, and local resident from his personal experience. When, in his capacity as tour guide, he took a group of tourists to a Balinese temple festival to see an event not normally on the tour schedule, he noticed another anthropologist, Hildred Geertz, in the temple compound conducting research. Although she accepted Bruner the anthropologist, she shunned Bruner the tour guide, reacting coldly to his offer to introduce her to his group of tourists.

This particular postmodern pastiche, which occurred in the temple compound, encapsulates much of the volume's main message-namely that by engaging in borderzone activity, anthropologists can disrupt their previously dominant and limiting binaries of ethnography-tourism and authentic-inauthentic. By engaging with tourism as a system in its own right, ethnography can become a much richer and more exciting enterprise.

\section{REFERENCE CITED}

MacCannell, Dean

1976 Staged Authenticity. In The Tourist: A New Theory of the Leisure Class. Pp. 91-107. New York: Schocken.

After Kinship. Janet Carsten. Cambridge: Cambridge University Press, 2004. 216 pp.

\section{KATHLEEN BARLOW}

Central Washington University

After Kinship is a crucial contribution to the paradigm shift in anthropological analyses of kinship, initiated most prominently in the work of David Schneider and Marilyn Strathern. Janet Carsten quickly reveals that the title of her book is playful, because "'after kinship' is-well, just more kinship (even if it might be of a slightly different kind.)" (p. xi). She connects contemporary issues in kinship to discussions of house, person, gender, substance, and new reproductive technologies: discussions that have largely supplanted kinship in anthropology for the past several decades. In doing so, she develops new ground for studying kinship and relatedness by questioning and moving beyond a series of limiting dichotomies: nature-culture, biological-social, substance-code, and the reigning distinctions between Western and non-Western societies.

She begins with intriguing contemporary examples: (1) the case of Diane Blood, whom British courts denied the right to be impregnated with her deceased husband's sperm; (2) rabbinic debates in Israel over solutions to infertility problems and the maternal basis of Jewish identity; and (3) adoption reunions in Scotland in which establishing biological connectedness was but one poignant step in often problematic and emotional efforts to establish relationships. Carsten explores how these activities express cultural expectations about kin and relatedness yet confound conventional ways of thinking about them. She weaves these stories into discussions of substance, gender, 
and state politics, pointing out critical differences between anthropological analyses and lived experiences. Using rich examples from other ethnographic work, she reveals that discussions about the social, cultural, and metaphorical processes by which kinship is established and negotiated in different communities have been ongoing. Her analytic synthesis of this refiguring is a tour de force.

Because earlier frameworks (alliance, descent, and marriage as exchange) did not keep pace with the political realities of postcolonialism, questions of power, production, gender, and hegemony moved into the foreground, shifting attention from abstract theoretical debates to the politics of everyday life. Schneider, investigating the meanings of kinship in U.S. culture, asserted that the biological and social aspects of kinship, fundamental to Euro-American folk models, had unwittingly and inappropriately become the terms of anthropological analysis. Strathern questioned "nature" as a universal concept associated with women, and then showed how gender and person were both fluid and partible in Melanesian (namely Hagen) society. Kinship seemed set adrift. How, without a basis in biology or nature, did societies and individuals form kin relationships?

Several discussions have contributed to new understandings about social relatedness. Carstens explores discussions of the house (household), gender, person, and substance. She develops a perspective on kinship as fluid, bridging domestic realms and wider political realities and full of emotional power and creativity. Houses and hearths symbolically encode the terms of relatedness as part of a cultural worldview. Studies of gender reveal ways of marking sameness and difference, but not necessarily according to "preconstructed" biology.

Substance in relation to kinship has been used to describe what is transmitted and mutable as well as what is permanent and essential. Thus, blood, sexual fluids, and food express qualities of spirituality, reproductive capacity, and relatedness differently in different societies. Her overall point is that substance is a fruitful analytic term because it draws together material and abstract aspects of person, body, and gender that previously have been underarticulated in kinship analyses.

Carsten also critiques the frequently used contrast between the autonomous individual of Western societies and the relational person of non-Western societies. She points out that both types of societies may defy such polarized distinctions. For example, women in patrilineal Chinese society are in some ways drastically individualized, and informants in her Scottish adoption cases invoked relatedness as essential to their wholeness as persons.

Carsten concludes with several chapters that reveal the many ways in which issues of kinship are ubiquitous and vital in contemporary societies. She examines the power of kinship as metaphor to create new forms of relatedness, to express ideologies of nation and state, and to imbue such ideologies with inordinate emotional power. The contemporary instability of technology and scientific knowledge challenges conventional terms of kinship, such as parenting, incest, adultery, and illegitimacy, with disturbing new questions and possibilities. Kinship beliefs are not only emotionally powerful, but powerfully motivated. In conclusion, Carsten suggests that kinship is not just complex, but creative, imaginative, "subtle and sophisticated," (p. 183) and that our analyses need to explore the dynamics of kinship in a broader comparative field and interrogate the old dichotomies as cultural tropes. Carsten productively charts that terrain and suggests some of the parameters for this new analytical project.

Mapping Yoruba Networks: Power and Agency in the Making of Transnational Communities. Kamari Maxine Clarke. Durham, NC: Duke University Press, 2004. 345 pp.

\section{DARRYL VICTOR CATERINE}

Grinnell College

Kamari Maxine Clarke's Mapping Yoruba Networks: Power and Agency in the Making of Transnational Communities is a descriptively rich and theoretically nuanced ethnographic analysis of Oyotunji African Village, an intentional religious community in Beaufort, South Carolina. Oyotunji Village was founded in the mid-1960s by Serge King, one of the first U.S. citizens to be initiated into Afro-Cuban Santería. Transformed by the ideals of black nationalism and the black power movement, King renamed himself Adefunmi and helped establish the orisha voodoo tradition in an effort to rid Yoruban religion of its "white" (Spanish-, French-, or Portuguese-Catholic) elements. Yoruban revivalism has continued since the 1960s to seek a "pure" African religiosity through academic study and tutelage under Nigerian practitioners. By analyzing orisha voodoo in its interactions with Nigerian and Cuban-Cuban American traditions, and its continuities with African American history, Clarke succeeds brilliantly in problematizing constructions of race, culture, and homeland as politically strategic discourses invoked in discrete settings that both replicate and challenge modern nationalist formations of race.

Clarke's theoretical departure point is the work of Arjun Appadurai, who argues that late transnational capitalism has unleashed the imaginaries of communities seeking to reestablish cultural orientation in the wake of ruptures and displacements. Globalization also contributes to a worldwide flow of religious myths and rituals that, disembedded from their preexistent contexts, can be appropriated by communities elsewhere. The most vivid illustration of these transnational dynamics in Clarke's study is the use of Samuel Johnson's 1921 History of the Yorubas as the foundational myth of Oyotunji Village. Johnson's work was produced during the era of British colonialism in Nigeria as a distinctively modern narrative of Yoruban identity, a tale of a lost homeland. Clarke's transnational "mapping" of this particular text illustrates how state-making apparatuses can be utilized by counterhegemonic communities, whose legitimacy is assured through their mimesis of hegemonic constructions of space, time, and community in religious mythologies. 
Notwithstanding their reliance on the legitimacy of nationalist imaginaries, Yorbuan revivalists ultimately derive their moral authority from the ideals championed in the black power movement. Although Yoruban revivalism's equation of blackness with African heritage received impetus from the conflation of biological and cultural classifications of race in the 1970s and 1980s, the dual narrative of slavery and African nobility-redemption emerged in the 1960s as a continuation of earlier black nationalist narratives. The reader of Clarke's work is thus confronted not by one but two theses: an application of Appadurai's transnational theories to Oyotunji Village, and a historical analysis of the origins of Yoruban revivalism that predates the accelerated processes of globalization. Oyotunji Village is the product of longstanding struggles by African Americans to find redemption in the wake of slavery and oppression. Its transnational dimensions (websites, routinized pilgrimages to Nigeria, and commodification and marketing of ritual objects) increasingly develop as the 20th century unfolds, and are also noticed more clearly in its origins from the vantage point of the globalized 21st century.

It is in fact the theme of redemption that emerges as a central though somewhat submerged organizing framework of Clarke's study. The master key for understanding how orisha voodoo redeems the subjectivities of its practitioners is found in her analysis of divination in Chapter 5. Reading Victor Turner's notion of "liminality" through the eyes of Andrew Apter and Giorgio Agamben as a "negative dialectic" and "state of exception," respectively, Clarke discusses how the ritual of divination effects a momentary suspension of inherited subjectivities so that new ones can be invoked and internalized by the participants. In light of this discussion, the reader is given more insight into the ability of Oyotunji villagers to selectively remember and forget African and African American ancestors in the context of the Egungun ceremony, which Clarke analyzes as a means of articulating collective identity and membership in Chapter 4. And finally, the reader is curious to know more about the discursive and social ruptures (as opposed to "movements") of the 1960s that gave rise to Serge King's own "redemption" as Adefunmi. Answers to these questions might clarify the extent to which Yoruban revivalism is both the product of and precursor to the kind of globalized subjectivities discussed by Appadurai. They might also reveal how religion, even in its modernized forms, does not derive its legitimacy solely or even primarily from its replication of nationalist constructs: Negative dialectics, produced by ritual, serve an end in themselves.

Ruth Landes: A Life in Anthropology. Sally Cole. Lincoln: University of Nebraska Press, 2004. 299 pp.

\section{LENI M. SILVERSTEIN}

Northwestern University

When Ruth Landes journeyed to Brazil in 1938, just before the onset of World War II, she was one of the first in a succession of Columbia University anthropology gradu- ate students to look to Latin America for insights into our own social dilemmas. At that time, Landes was already a seasoned researcher; under the guidance of her mentor, Ruth Benedict, she had completed her dissertation, a traditional ethnography of the Ojibwa in Manitou Rapids, Canada. She had also concluded field trips to other Native ${ }^{\circledR}$ communities-the Chippewa (Ojibwa) in Red Lake and the easternmost Siouan-language speakers near Red Wing, both in Minnesota, and the southernmost Algonquian speakers, the Pottawatomie, in Kansas. During this period, she honed her considerable observational skills, her commitment to studying gender relations, and, as Sally Cole puts it, her "reflexive, multivocal, 'unscientific,' writing style" (p. 15). She appeared to be poised to register her distinctive mark on the emerging academic discipline of anthropology. Such was her immense potential that we have to wonder what went wrong; what happened during her Brazilian field work on race relations to relegate Landes and her pioneering work to the periphery of anthropology? Why, among all her inter-World War anthropological colleagues, was her work virtually ignored until the interest of feminist anthropologists resurrected her innovative voice and celebrated her contributions to the field?

Sally Cole's beautifully crafted intellectual biography of Ruth Landes reads like a sophisticated 21st-century cautionary tale, deliberately framed to tell the intertwined story of a smart, stubborn, creative, and lusty female anthropologist who was marginalized, blocked by the very discipline that nurtured her creativity. Cole uses a feminist lens to demonstrate that in Landes's case, the personal was political. Combining prodigious archival research with interviews with surviving family and professional contemporaries, Cole meticulously unravels the story of a feisty, young, intelligent, and beautiful woman, raised in a radical New York Jewish family of the 1920s, who discovers anthropology at Columbia University. The author locates the life of one anthropologist into, and as part of, the political context and theoretical debates that led to the shaping of anthropology as a discipline. Cole demonstrates how insufficient brains and brilliance were without the pivotal support of a mentor to secure funding; how patronage within "the academic old boys network" seamlessly provided jobs for the most promising male students (and assumed that females would be taken care of by their spouses); and how the fierce competition for intellectual territorial dominance left no room for naivete. Landes proved almost defenseless when maligned by Melville J. Herskovits as he attempted to exert his hegemony over "African cultures in the New World," or when undermined by Margaret Mead, who was possibly defending her preeminence as the principal female public intellectual and the interpreter of cross-cultural sexual mores. How personal jealousies, social insecurities, careless comments, and sexual rivalries might have contributed to Landes's banishment is judiciously handled in this thoughtful and measured account, one that never stoops to facile psychological formulations.

Nevertheless, Cole neither ignores nor trivializes Landes's personal contradictions as the title of her most 
revealing chapter, "She-Bull in Brazil's China Closet," makes plain. It is a wonder that Landes, so sensitive and insightful about non-U.S. cultural interactions, appeared to be so clueless and self-destructive at home. Inspired by Landes's City of Women, I conducted my own field investigation of the Candomble "matriarchies" during the 1970s and can, therefore, vouch for the tenacity of the social and political minefield that thwarted her investigation (as well as my own) at every step. Landes ignored the basic tenets of what I call Brazilian etiquette rules, the imperative of knowing to whom you are speaking: voce sabe com quem voce esta falando? Unconsciously flaunting class, racial, and professional hierarchies, Landes chose Edison Carneiro, an autodidact ethnographer, reporter, Communist, and mulatto, as her chief informant, chaperone, and lover, thereby attracting the enmity of those in power. Snubbing upperclass society in preference to lower-class racialized communities, she became an object of gossip and social approbation. Showing bad judgment and a lack of social awareness uncommon in most students of culture, Landes was undone by her tempestuous and uncompromising personality. Ignoring the niceties of Bahian upper-class society and its finely tuned patronage network in favor of love and ethnographic veracity, she became isolated from her natural support network. Through Carneiro, however, she gained access to the sexual, magical, and political world of Candomblé, whose terreiros, or cult houses, provided a "new and transgressive social space" (p. 195) in which homosexuality or transvestism could be expressed. Such observations angered Brazilian scholars, particularly Arthur Ramos, the gatekeeper of Brazilian anthropology, who formed an alliance with Herskovits to silence her original contribution.

Two aspects of Cole's subtle analysis appear incongruous; both deal with the overarching impact of politics on the evolution of Landes's theoretical interests and professional trajectory. First, there appears to be an inherent contradiction between Landes's intensive childhood exposure to progressive politics and her concomitant commitment to minority rights, and Cole's contention that Landes was not actively engaged in politics. Second, although Cole provides a compelling analysis of the personal and professional reasons behind the antipathy both Arthur Ramos and Melville Herskovits felt toward Landes, I believe she neglects their conflicting political agendas as well as their professional projects.

This book is elegantly written and beautifully produced. Each of the three sections is introduced by Sally Cole's reflections, both theoretical and personal, as she follows and interprets Ruth Landes's intellectual journey. The accompanying photographs provide documentary evidence of the intensity, vivacity, and beauty of Landes. Cole reconstitutes Landes as a principal player in the development of anthropological theory and methodology. Landes was clearly a woman ahead of her time, an anthropologist who was unwilling to ignore such taboo subjects as homosexuality and who insisted on transmitting the social veracities that her fieldwork revealed. She was also a woman who refused to dismiss intimacy and frequently allowed passion to cloud her judgment. Cole demonstrates the professional consequences that could accrue to one so intent on ignoring the very social conventions she sought to understand. This book is a must for all those interested in the history of the discipline, for aspiring anthropologists and Brazilianists as well as all graduate students, who, on reading this anthropological biography, can begin to appreciate how the field has changed-somewhat.

Threads: Gender, Labor, and Power in the Global Apparel Industry. Jane L. Collins. Chicago: University of Chicago Press, 2003. 207 pp.

\section{PAULINE GARDINER BARBER}

Dalhousie University

This ethnography of the new economy explores innovation in the global production and marketing of garments. Interviews with managers, workers, and union activists assess corporate decision making, ideologies, contradictions, and their consequences. Much has been written about the textile industry's pivotal role in the economic and social transformations of the industrial revolution. In the mid- to late 20th century, feminist research described an emergent division of labor whereby women in the global South produced garments for Western consumption. Debates ensued over the following: forms of production and social reproduction in global garment factories, labor process control and resistance, trajectories of capitalism, the role of states in the commodity chain, the significance of community and culture to production regimes, and, of course, the flexibility implications of new technologies in globally mobile firms. These are the precursory debates for this volume. So, how does Collin's ethnography contribute to this vast literature?

Threads provides a nuanced analysis of the complexities of the industry's reliance on "spatial fixes." Workers, corporate managers, and consumers are linked in a distinctive commodity chain, which is buyer driven, of low capital intensity, and heavily reliant on labor as a production factor. Searching out new sites for cheap labor-"greenfields"compels the globalization of the industry. Conceptually, the commodity chain provides the entry point to "the social relations of apparel production as these are restructured by local and global forces and enacted by employers and workers within their disparate and shared frameworks of meaning and power" (p. 6). Multisited ethnography, conducted in four plants (two in the United States, two in Mexico), reveals dramatic transformations underway in the industry. The book critically challenges three predominant arguments made by industry observers: (1) that the garment industry is but one stage in the "evolution" of economic development for countries in the global South; (2) that high-end production, requiring more skill, results in more humane labor practices; and (3) that paternalistic labor practices were ruthless, for example in U.S. mill towns where companies were a powerful community presence. 
How, Collins asks, might new transnational communities of activists pressure greater accountability from the industry? How do we define development without considering social well-being? Here she speaks to the failure of the industry to provide wages commensurate with the costs of social reproduction in local economies.

Collins's mapping of the industry exposes various familiar and new contradictions in the discourse of skill, its gendered qualities, and geographic locations. Women's lower wages are facilitated by ideologies about gender and skill, but this is socially accomplished context by context. Skill, rather than technical capability, is subject to "claim making" (p. 171). Because of a "naturalization paradigm," sewing is typically regarded as a female aptitude, reproduced through culturally specific socialization. Expressing what seems to be an about face on the question of sewing skill, managers lamented that "we've lost the ability to sew in America" (p. 172). So companies now acknowledge that sewing requires skill and that they rely on the specialized skills of workers in particular regions of global labor markets. However, by juxtaposing claims by managers and workers, Collins shows how discourses about skill decline in the United States provide a rationale for moving production offshore. Paradoxically, such arguments suggest that women's employment ruptures the process of the domestic transmission of sewing skills. The stage is then set, ideologically, to justify the relocation of production. Collins argues, it is not that women lose the ability to sew. Rather, as some workers come to appreciate the comparative value of their sewing skills, management logic and the "naturalization paradigm" become ineffective in countering claims to skill (p. 176).

Collins unpacks the powerful ideologies that promote the relentless quest for locations where the balance of gendered skill, labor costs, and culture and community dynamics render production profitable. Her challenge to contemporary ideas about a geographic division between high-end (better waged) and low-end production is relevant here. Yes, skill becomes one determinant in decisions about subcontracting and outsourcing locations. But the reinvention of Taylorism and intensified work routines operate in factories producing for the top and bottom ends of the fashion industry. Quick-response systems and flexible work practices plus new skill requirements add more job stress. And nowhere are wage rates sufficient to sustain workers (let alone dependents). Despite the gendered logic of women's wages as supplemental, many sewers provide the primary income for their households. This makes the wages inhumane.

In sum, this readable, well-researched ethnography offers much empirically and analytically for informed scholars, students, and a general readership curious about why clothing is usually from elsewhere. If there is any discernable flaw, it relates to the volume's political vision. Is the presentation of ethnographic evidence for collaborative activism overly optimistic given that the industry pits workers producing for the same firm in different locations in direct competition with each other? One hopes not.
Anthropology in the Margins of the State. Veena Das and Deborah Poole, eds. Santa Fe: School of American Research Press, 2004. 330 pp.

\section{ROBERT M. HAYDEN}

University of Pittsburgh

The participants in the 2001 School of American Research (SAR) advanced seminar, from which these chapters stem, were asked to "reflect on what would constitute the ethnography of the state as embodied in practices, places and languages conceived to be at the margins of the nation-state" (p. 3). The conference conveners and volume editors, Veena Das and Deborah Poole, wished to distance the discussion from images of the state as a political or administrative form that weakens at its margins. Instead, they wanted to look at how practices and politics at territorial or social margins shape the practices that constitute "the state." Explicitly keeping to the traditional role of anthropology as looking at the geopolitical margins, the chapters here are on Africa, Latin America, and South Asia.

The chapters themselves are of high quality but very heterogenous in focus. The editors say that their discussions led them to formulate three concepts of margins. The first is that of margins as peripheries, the perspective adopted by most contributors. Three chapters deal with populations labeled "indigenous" and, thus, seen as subjects to be managed, in Guatemala (Diane Nelson), Peru (Deborah Poole), and South Africa (Adam Ashforth). Three more analyze control mechanisms over peoples displaced by wars, in Chad (Janet Roitman), Colombia (Victoria Sanford), Sierra Leone (Mariane Ferme), and Sri Lanka (Pradeep Jeganathan). Das, however, focuses on the "illegibility" of state practiceshow state practices, documents, and words are often unintelligible to the people on whom they are forced. Although her own chapter deals specifically with India, Das's arguments resonate with the analyses of the use of documents such as identification cards or passports in many of the other chapters. Another focus, the margin as "a space between bodies, law and discipline," is most clearly set out in Lawrence Cohen's chapter on "operability" in India. Cohen gives a close analysis of legal and social forms that render some bodies "bioavailable" as donors for the redistribution of human tissues, others as "operable" in that they may be subjected to surgical intervention by the state, and some are "supplemental," enabled to receive the tissues of the operable. Again there is resonance with other chapters in the realms of state assertion of control over the population as a biomass-a "biopolitical" state.

As is customary in such volumes, the separate studies reported in the chapters are bracketed by an introduction by the editors and concluding remarks, in this case by Talal Asad. Das and Poole's introduction does a skillful job of revealing the warp and woof of the theoretical strands that connect the various chapters, and does some weaving of its own to assemble a single product from the separate pieces. Das and Poole remind us that although the margins 
in question are defined by state efforts to control populations, the manipulations that people make of state institutions may at times "reconfigure the state as a margin to the citizen-body" (p. 30). For his part, Asad concisely reformulates the definition of the margins as being "the places where state law and order continually have to be reestablished" (p. 279), thus recognizing the locus as manifesting both state efforts at control and popular manipulation of the state.

Asad's conclusion goes beyond the arguments of the editors or the other contributors in asserting that the officials of a state truly bound by law would treat citizens with indifference. Further, he argues that because populations are not homogenous, and "categorization always involves abstraction from one context and its application to another," placement into formal categories it is always uncertain (p. 283). Thus, to Asad the margins of the state always rest on uncertainty. At this point the themes raised in this collection could connect with long-standing theoretical debates in Europeanist sociology (Max Weber's formal and substantive rationalities and bureaucracy) and anthropology (Louis Dumont's analyses of equality and individualism, Michael Herzfeld on the social production of indifference), although Asad does not do so. It is, thus, perhaps unfortunate that this collection does not have an analysis of one of the European states that failed in the 1990s (the Soviet Union, Yugoslavia, or Bosnia) or that may be failing now (the "self-determination and autonomy" of the Basque region of Spain). However, because so much of the discussion in this volume is relevant to those cases, Das and Poole have succeeded in the classical anthropological move of using ethnography from the geopolitical margins to develop issues relevant to the metropolitan center as well.

The Gift in Sixteenth-Century France. Natalie Zemon Davis. Madison: University of Wisconsin Press. 2000. 196 pp.

\section{EMIKO OHNUKI-TIERNEY}

University of Wisconsin, Madison

Natalie Zemon Davis, author of The Return of Martin Guerre (1983), is a preeminent figure both in history and anthropology. The famous collaboration at the Shelby Cullom Davis Center for Historical Studies at Princeton University, between anthropologist Clifford Geertz and historians Natalie Zemon Davis and Robert Darnton, initiated a long tradition of vibrant interaction between the two disciplines. Davis's work on 16th-century French history has been consistently informed by anthropology. In turn, we learn from her how to historicize anthropology. Davis's book on the gift-oil that greases the wheel of sociality in almost all societies-is a treasure, ethnographically and theoretically. The originality of her insight shines most brilliantly in two areas: the ambivalence of the gift and the gift when it misfires-its darker and murkier sides. In her words, "The bad gift will also have an important role in this study" (p. 9).
The theoretical framework of her "ethnography of gifts in sixteenth-century France" (p. 9) is a "gift register" or a "gift mode," which exists along with the mode of sales of the market economy and the mode of coercion (theft, punitive seizure, taxes, etc.).

The book begins with an introduction of two major principles-a gift of God and reciprocity in this world. The latter is expressed in "The Three Graces," represented as three circling sisters: "One of them bestoweth the good turne, the other receiveth it, and the third requiteth it" (pp. 12-13). Christian charity (in which God alone offers the return to the donor), secular liberality (not anonymous), friendly affection, and neighborliness were the modes of reciprocity through which feelings and virtues were expressed, with the Three Graces sometimes in concert and other times missing a step.

After a discussion of gift-giving practices along calendric events in Chapter 2, Davis introduces gift practices in social occasions between kin and neighbors, detailing the occasions, social contexts, and types of gifts. Never drawing a sharp line, in Chapter 4 Davis illustrates differences between gifts and sales. The next chapter, called "Gifts Gone Wrong," is a gem. Davis illustrates how this Pandora's box contains mixed blessings. She begins with parental "gifts," which include the choice for marriage and religion for the offspring - a historically specific phenomenon at the time when the future possibilities for children became more varied. Litigation, revocation of a donation, bodily harm, gross insult, and even murder are other examples of gifts that went wrong. "Gifts, Bribes, and Kings" is about gifts that are offered to the politically powerful or socially necessary, such as lawyers. In Chapter 7, we return to the importance of religion in "Gifts and the Gods," with Davis's incisive analyses of the exchange between the living and the dead, laity and clergy, and sacrifice. This leads her to conclude that the place and role of gifts in the Protestant Reformation was "not 'caused' by conflict in family and political life, nor was it a 'reflection' of the same. ... But the issues it raised nourished long-term political reflection about the obligations of kings and the claims of subjects, and prompted both Catholic reform and Protestant innovation" (pp. 124-25).

Throughout the book, she pays attention to the class and gender of the individuals, so that we get a picture of the intricate mosaics of the whole society. She finds that men's "sense of autonomy [was] quite distinctively masculine" (p. 76), whereas women sought public favor not for themselves but for their family, especially for their sons (p. 76). Illuminating passages from "Exodus," the Iliad, King Lear, and descriptions of the Tupinamba remind us that the gift in 16th century France shares motives, interests, and modes of transactions with peoples in other times and places.

One dimension of the gift, not foregrounded in this book, is the relationship between the donor and the object of gift-alienable versus inalienable. It is an important dimension when we ponder such "new" gift phenomena as organ donation. Because the body is the seat of personhood in any social group, an organ is as inalienable as an object 
can be, but in today's practice it is given to total strangers, easily turning the gift of self into a commodity.

Scholars interested in exchange, sociality, and historical anthropology will find this book exceptional, offering methodological and analytical models, as well as rich and complex historical ethnography. Readers of all levels, whether the educated general public, undergraduates, or graduate students, will learn from this book-indeed, a splendid gift to all of us.

\section{REFERENCE CITED}

Davis, Natalie Zemon

1983 The Return of Martin Guerre. Cambridge, MA: Harvard University Press.

Indian and Nation in Revolutionary Mexico. Alexander S. Dawson. Tucson: University of Arizona Press, 2004. $240 \mathrm{pp}$.

\section{BRIAN D. HALEY}

State University of New York College at Oneonta

In this well-crafted book, Alexander S. Dawson explores the nexus of social science, revolutionary nationalism, and political participation by indigenous communities in postrevolutionary Mexico. Dawson tells the history of revolutionary indigenismo (indigenism) during the 1910s to 1940s, whose chief intellectuals-Manuel Gamio, Carlos Basauri, Moisés Sáenz, Luis Chávez Orozco, and others-strove to create a modern Mexico by creating modern Indians. These Indigenistas and supportive elites believed that achieving a modern nation hinged on "undermining local autonomy throughout the country by instituting a new secular and modern set of cultural beliefs, a new property regime, new political institutions, and new infrastructures" (p. xvii). ${ }^{1}$ It would require convincing Mexicans that indígenas could be rational political actors and developing participatory citizens through a sequence of federal programs: an Indian school in Mexico City called the Casa del Estudiante Indígena, internados indígenas (Indian boarding schools), Departamento de Asuntos Indígenas (Department of Indigenous Affairs, or DAI), and Congresos Regionales Indígenas (Regional Indigenous Congresses). Dawson provides readers with a richly contextualized history of a major episode in applied anthropology and a focused case study of the ideology and practice of nationalism. By demonstrating that diverse actors shaped revolutionary hegemony through these programs in various ways, he challenges past influential critiques of Indigenista social science that dismiss it as an Orientalist stage in the history of Mexican anthropology.

A simplistic assimilationism underlay the Indigenistas' earliest efforts, bringing ambiguous results as a consequence. Manuel Gamio, who studied under Boas, argued that anthropology offered the potential to unite all Mexicans into one culture, and after 1917 used the Dirección de Antropología (Directorate of Anthropology) to carry out studies intended to redeem Indians by denying their alleged biological inferiority. Although they challenged biological determinism, the indígenistas were constrained by racial ideology and did not overcome the idea of Indian alterity. The first program designed to prove that Indians could be fully modernized was the Casa del Estudiante Indigena (House of the Indigenous Student) boarding school. Although its students demonstrated a capacity for education and citizenship, its emphasis on artistic achievement also reinforced Indian alterity. The first round of programs ended when Sáenz's 1932 project in Carapan, Michoacán, failed because of native resistance, forcing Indigenistas to acknowledge that simple unilinear assimilation was unlikely to succeed.

New rural Indian boarding schools after 1933, the internados indígenas, adopted a pluralistic approach: bilingualbicultural practices specific to their settings and an emphasis on creation of leaders who would become local agents of progress. President Lázaro Cárdenas promoted the program after 1936 because the internados permitted his administration to create new political allies. Communities welcomed the schools because of their openness and the opportunity they offered. The internados have been criticized for association with factional disputes, abuses by directors, and for strengthening ethnic barriers. But Dawson claims these shortcomings were specific to particular localities and that the internados overall succeeded in their educational mission, empowered local communities, and produced graduates who helped shape the nation. The DAI under Orozco portrayed cultural diversity as a source of national strength. But Cárdenas did not support cultural pluralism, and Gamio's and Basauri's emphasis on poverty rather than culture as the source of difference between indígenas and the mestizo mainstream played into the nationalists' hands.

The Congresos Regionales Indígenas were instituted to provide the Cardenista state with a mechanism for building alliances with indigenous Mexicans. They also provided an opportunity for a new cohort of bilingual young men-the indígenas capacitados-to arise as leaders of Indian communities and as their key intermediaries with the state. In the 1940s, Mexico rejected pluralism, returned to a unilinear approach to modernization, and social science ceased being nationalistic. Dawson notes that the Indigenistas failed to uproot the negative image of indígenas common among mestizos. Yet drawing from the ideas of Lomnitz, Roseberry, and Bourdieu, he also compellingly argues that the capacitados emerged from the very programs that have often been described as failures: the Casa, internados, and other activities of the DAI. Their emergence, according to Dawson, was the most important outcome of Revolutionary Indigenismo and played a central role in sustaining the rule of the Partido Revolucionario Institucional (Institutional Revolutionary Party, or PRI). In the Congresos, they demonstrated support for the state and petitioned it for resources while attempting to preserve limited autonomy for their communities. Thus, Dawson sees Revolutionary Indigenismo not simply as an Orientalist enterprise, but as a "common discursive framework" in which indigenous actors could contest and shape national hegemony-albeit from a position of dependence within revolutionary nationalism. This well-written 
book should inspire a more nuanced reappraisal of other episodes in the history of applied anthropology.

\section{NOTE}

1. The book's author capitalizes Indigenistas throughout his text, presumably to distinguish this specific group of professionals who are his focus from a more general meaning of the term.

Collapse: How Societies Choose to Fail or Succeed. Jared Diamond. New York: Viking, 2005. 575 pp.

\section{HECTOR QIRKO}

University of Tennessee

In this book, Diamond proposes and supports a five-factor model through which to understand patterns of present and past societal collapse. He means his work to serve as a warning of the dangers facing the modern world, and, for those who are willing to negotiate its nearly 600 pages, it makes a persuasive case. His model focuses on the societal impact of environmental damage, climate change, hostile neighbors, withdrawal of support of friendly neighbors, and cultural responses. The book is in four parts. It begins with an analysis of the state of Montana, which is followed by a section on past failed societies, including Easter, Pitcairn, and Tikopia Islanders, and the Anasazi, Maya, and Norse Greenlanders. Part 3 discusses modern-day Rwanda, the Dominican Republic, Haiti, China, and Australia. The final section, entitled "Practical Lessons," summarizes the factors associated with disastrous societal decisions, big business's impact on the environment, and implications for the future.

Although Diamond's writing is as strong and clear as ever, the book is less sure of what it wants to be than some of his earlier works, notably The Third Chimpanzee (1992) and Guns, Germs, and Steel (1997). It is at once analytical and anecdotal, and occasionally even something of a personal travel journal. There are also some methodological problems: The discussion of Montana is troublesome, as it is of course only part of a society. Why it merits inclusion on its own is not made sufficiently clear. How success or failure should be defined is also problematic-some of his collapsed societies survived 500 years, a span that might be taken (esp. by U.S. citizens celebrating a scant 230 years as a nation) as a measure of success.

These issues aside, the book is powerful and illuminating when addressing environmental, climatic, and economic factors associated with societal collapse. Its use of archaeological data to inform past catastrophes is also effective. But in the area of "choice" - that is, of cultural responses-it somewhat disappoints. Diamond's own analysis makes it clear that, in many cases, societies are not choosing at all but, rather, are at the mercy of processes which they can have no awareness or control. Even where societal choices can be and are made, the discussion of cultural forces influencing them is less than persuasive. His best case for the power of choice is the dramatic collapse of the Norse Greenlanders, to whom he devotes two chapters. He ultimately blames cultural conservatism, especially around practices that were successful in the past, for the fact that Greenlanders failed to adopt innovations they had every opportunity to borrow from neighboring Inuit. Yet anthropological literature is replete with examples of dramatic culture change, as well as discussion of specific forces that influence the adoption and diffusion of innovations. Work on human cognition, especially with respect to short- and long-term thinking, cost-benefit assessments, "bounded" rationality, and conformity, is also highly relevant. And who is doing the choosing anyway? He often couches his discussion at the group level, but this can minimize the potential contribution of individual level dynamics, as in the case of competing leaders destroying societal resources for individual gain. If we are to seriously explore the impact of cultural choices on societal survival, all of these perspectives need to be taken more fully into account.

Thus, some of Diamond's conclusions with respect to choice are simplistic - for example, his analysis of the differences between the Dominican Republic and Haiti, as respectively successful and collapsing societies, centers on the consequences of the Haitian slave revolt on relations with colonial powers, as well as on the differences between the two nations' respective despots. Yet what "choices" would he have had members of these societies make? Remain enslaved to better promote friendly relations? Overthrow Papa Doc but keep Trujillo because of the more benign, if selfserving, environmental practices of the latter? The answer one is often left with, rather than his suggestion that "a society's fate lies in its own hands and depends substantially on its own choices" (p. 341), is that environmental, historical, and political accidents play the largest role in societal success or failure. And these forces are, by definition, not in the realm of choice at all.

All in all, however, this is a fine comparative overview of a number of societies and their relationship to the environment. It is also a well-told cautionary tale about the need for members of modern societies to start paying attention, as collapse, rather than a historical anomaly or an archaeological mystery, remains a very real possibility for even the richest and most powerful nations.

\section{REFERENCE CITED}

Diamond, Jared

1992 The Third Chimpanzee: The Evolution and Future of the Human Animal. New York: Harper Collins Publishers.

1997 Guns, Germs, and Steel: The Fates of Human Societies. New York: W. W. Norton and Company.

Stitches on Time: Colonial Textures and Postcolonial Tangles. Saurabh Dube. Durham, NC: Duke University Press, 2004. 259 pp.

\section{DAVID LUDDEN}

University of Pennsylvania

Fifteen years ago, Gyan Prakash argued that historical writing about India reached its fulfillment by becoming postcolonial criticism, under the sign of subaltern studies. This attracted criticism from David Washbrook and Rosalind 
O'Hanlon, who argued that historical research should remain accountable to established standards of veracity and relevance. Such disputes have now disappeared in the United States, where postcolonialism has formed an academic niche inside cultural studies, which straddles several disciplines, and where Indian history, anthropology, and cultural studies have become indistinguishable in trendsetting universities, following a trend launched at the University of Chicago in the late 1980s. Major university pressesnotably Chicago, Duke, Princeton, and Minnesota-have successfully marketed India as a postcolonial field, dramatically increasing the supply of books that consider Indian history, without limiting their market to Indian history.

Indian history, thus, need not be history anymore-it can be many things-and marketing India as a postcolonial problematic has produced various chameleon genres, which is where I would locate Saurabh Dube's Stitches on Time. Dube himself calls the "rubric" of his book "history without warranty," a "disposition" (not discipline), which forms "a possible means of calling into question the guarantees of progress under regimes of modernity" (p. 20). In this book, he seeks to provide critical leverage on colonialism and its entanglements in the everyday subaltern life, but instead, he dissolves Indian history into postcolonialism.

All traces of spatial and temporal context disappear here in narrative fragments plopped into an anthropological present spanning the last century and a half. The first four chapters consider missionary activity and social conflict in the Chhattisgarh region of central India, a context so unimportant to the author that he omits its name from the index. Although the 1930s Depression is important, it likewise disappears along with other markers of historical time. In the absence of space and time, it is difficult to imagine a postcolonial anything, but the last three chapters nonetheless jump into historical ideas in subaltern studies and Hindu nationalism (Hindutva), without considering either as being located inside Indian history after 1947.

This rhetorically ambitious, substantively disappointing book missed numerous opportunities to make major breakthroughs. The first four chapters open new windows into important subjects, above all, conversion and village conflict. The last three add nothing substantial. All the chapters could have been woven together powerfully by focusing on missionary conversion as a colonial and postcolonial problem, ignored by subaltern studies and obsessively embraced by Hindutva. Dube has reduced the method of studying "fragments" to a theoretically convenient anecdotalism that obscures obvious connections and intriguing possibilities. It appears, for instance, that Dube implicitly endorses the Hindutva idea that missionaries in British India were elite aliens who bought poor converts with material benefits. Dube ignores critical work by Gauri Viswanathan, indicating his lack of concern for the ontology, let alone politics, of colonial Christianity. It would have been fascinating to see how conversion influenced social conflicts and solidarities in Chhattisgarh and to see how subaltern studies would treat convert ideas of subaltern empowerment, Christian ideas about dalit and adivasi uplift, and Hindutva's hatred of missionaries. Was conversion subaltern resistance or colonial capitulation? One route into this topic, implied by Dube but dropped, would have been to compare colonial Christian conversion in Spanish America and British India. Addressing directly questions about Christian conversion in postcolonial studies and India would have made this book more useful.

Dodging difficult issues weakens any critical intervention, and the touchiest of the postcolonial entanglements dodged in this book-which Dube does raise implicitly as a topic for further research-concerns the imbrication of subaltern studies and Hindutva with political trends in India since 1980. Subalternism and Hindutva attained their current prominence amidst trends that distinguish the 1990s. Both rose in opposition to Indian nationalism. Both promulgate skepticism about modernity, empiricism, universalism, Enlightenment, Marxism, and progress. Both promise liberation from colonial legacies. Both represent the nation in its elemental form. Both deploy decontextualized fragments. Both have flourished in the United States, where they coexist. Dube says that Gyanendra Pandey's famous praise of the "fragment" appeared at the same time as Hindutva's demolition of the Babri mosque in Ayohdya, in 1992 (p. 176). But what does he make of this moment of contextualization? Nothing.

The Curious Feminist: Searching for Women in a New Age of Empire. Cynthia Enloe. Berkeley: University of California Press, 2004. 367 pp.

\section{SUSAN HANGEN}

Ramapo College

In this collection, Cynthia Enloe seeks to demonstrate the relevance of feminist approaches for analyzing contemporary issues in international politics. Enloe argues that by asking feminist questions and by taking women's lives and experiences seriously, scholars can make sense of a whole range of political processes, not just those that affect women, in particular.

The Curious Feminist serves as a retrospective of Enloe's feminist work, which has been influential throughout the social sciences, and also highlights her role as a public intellectual. Most of these chapters have been published elsewhere, including several short pieces critiquing militarism and the labor practices of multinational corporations that appeared in Ms. magazine. Interspersed with these chapters are four fascinating "conversations with Cynthia Enloe." The book reveals that Enloe is an unusual scholar who is committed to making political theorizing "part of the hubbub of the public arena" (p. 253).

This volume is particularly relevant for anthropologists in several ways. Although trained as a political scientist, Enloe employs methods and theoretical approaches that are central to the anthropological enterprise. For example, in her introduction, in which she expounds on the value of 
a "feminist curiosity," she calls for scholars to question the concepts of "natural," "traditional," and "always" (pp. 1-3), a practice that has long lay at the heart of anthropology. In addition, she applauds ethnographic research methods when she praises research inspired by a feminist curiosity for looking at informal conversations as well as public discourse (p. 5). She notes that she makes extensive use of "feministinformed, historically minded ethnography" in her own research and writing (p. 251). Furthermore, in Chapter 2, "Margins, Silences and Bottom Rungs," Enloe hails the importance of examining the margins, the traditional focus of anthropological research, to understand the complexity of the workings of the state. In using these anthropological methods and concepts, Enloe's ultimate objective is not just to understand women's lives but also to understand what women's lives can reveal about the workings of the wider political system. Herein lies an important lesson for anthropologists about the value and relevance of the discipline to understanding political processes.

Some of the older essays in this volume, such as Chapters 3 and 4 on women in the global factory, will yield little new information for anthropologists who have been following the extensive ethnography on this topic. However, scholars of ethnic and nationalist politics could find much inspiration from the astute questions that Enloe raises in Chapter 7, "All the Men Are in the Militias, All the Women Are Victims." Here, she argues that without examining gender, we will have "an imperfect understanding of how ethnic and nationalist processes actually operate" (p. 103). By exploring the case of a man who joined a Serbian militia group and was tried for committing mass rape, she presents a model for how scholars might go about investigating the gendered aspects of ethnic and nationalist conflict.

Throughout the book, Enloe uses the term patriarchy, which she defines as "the structural and ideological system that perpetuates the privileging of masculinity" (p. 4). One of her more provocative arguments is that "patriarchy may hold the causal key" when explaining international political processes (p. 7). This argument is most fruitfully applied in Chapters 9, 11 and 13, in which Enloe demonstrates how dominant constructions of masculinity have contributed to the increasing militarization of U.S. foreign policy. However, although patriarchy as a social force may explain some of the ways in which foreign policy formation, empire building, and globalization take place, Enloe has further to go to prove that the concept can be used independently of explanations that focus on economic processes.

The final section of the book consists of six poemlength pieces of prose in which Enloe ruminates about her own girlhood and her early encounters with militarization. This section will intrigue readers who have become interested in learning more about the author. Yet although these pieces reveal the connections between her childhood experiences and topics that became the focus of her research projects, this experiment in reflexivity might work better if it were integrated with the theoretical material and further analyzed.
Because of her interest in having her work read beyond the academy, Enloe writes in a clear, accessible style. Many of the chapters included here will work well in undergraduate classes on cultural anthropology, gender, and international studies. This engaging book may also inspire anthropologists and other social scientists, even committed feminists, to embrace Enloe's mode of feminist investigation.

Yali's Question: Sugar, Culture, and History. Frederick Errington and Deborah Gewertz. Chicago: University of Chicago Press, 2004. 319 pp.

\section{RICHARD SCAGLION}

University of Pittsburgh

The title of this engaging ethnography of a sugar estate, development project, and social experiment in the Upper Ramu Valley of Papua New Guinea (PNG) may be puzzling. In 1972, Jared Diamond, author of the Pulitzer Prizewinning Guns, Germs, and Steel (1997), conversed with Yali, a well-known "cargo cultist" who sought to bring Western commodities (cargo) to his people with magic and ritual. Yali had asked Diamond why "white people developed so much cargo ... but we black people had little cargo of our own?" (p. 7). Diamond used Yali's question to explain the privileged position of the "haves" as resulting not from merit, but from geographical advantages and the normal course of cultural evolution. That is, temperate climates were better suited for intensive agriculture and animal domestication. Ensuing warfare stimulated technological development and advanced social and industrial organization, which could then be employed to dominate peoples who had not developed immunities to disease.

Errington and Gewertz say that Diamond misunderstood Yali's question, and challenge Diamond's interpretation of 13,000 years of world history in his narrative of "grand inevitability" (p. 257). According to the authors, Yali was not asking about "things," but about social inequality. Why did Europeans deny fundamental moral worth to Papua New Guineans and refuse to engage with them as equals? Diamond's account assumes that those in power will invariably use it, a position refuted by Errington and Gewertz's history of Ramu Sugar Limited (RSL) that richly demonstrates how historically situated actors make choices that are culturally conditioned but not inevitable.

The authors develop the story of RSL through detailed and intersecting local, national, and international narratives. It begins in the 1950s and 1960s with government officers' development plans for the Upper Ramu Valley. Some 40,000 acres of little-used grassland were purchased from local people and leased to Australians to establish cattle stations. In the early 1970s, with the approach of selfgovernment, the possibility of creating a national sugar industry was raised by a series of economic studies on development alternatives. A complex and contested decisionmaking process resulted in the establishment of RSL over other options. In the otherwise remote Upper Ramu Valley, there soon emerged "a vista of green cane fields, a traffic of 
heavy equipment, a rumble of cane-crushing rollers, and a community of thousands" (p. 65), as well as a "Dickensian, smoke-belching, steam-shrieking factory" (p. 1).

Through personal accounts, the authors explore how RSL developed as a place and social entity, shaping the lives of the thousands who live there. These include the expatriates from the United Kingdom, Australia, and elsewhere, who supervised the construction of the estate and now manage it; the Papua New Guineans who work there; and the local landowners who sell cane to RSL, make claims on it, and seek to profit from it. Because RSL drew labor from all over the country, it soon became a unique PNG location, where local allegiances, at least partially, have given way to a new and diverse sense of community. Making sugar at RSL has, thus, been part of building a new Papua New Guinea. But RSL is under threat. By worldwide standards, its annual capacity of some 30,000 tons of high-quality refined sugar, although adequate for PNG's needs, is actually modest, and the sugar is costly to produce. RSL cannot compete without the government tariff protection that advocates of "free trade" and globalization would reduce or terminate. The authors argue convincingly that the collapse of RSL would result in local hardship with little or no gain elsewhere in PNG's troubled economy.

Ethnographic studies in Papua New Guinea have taught us much about human nature, but often from the vantage point of small villages at the margins of global forces. In contrast, Errington and Gewertz depict a diverse and complex social context at the very center of contemporary economic and social global controversies. Thirty years of research in PNG provides them with the background to produce this even-handed and well-balanced trenchant analysis that gives equal voice to the expatriates, PNG elites, and local landowners who together constitute RSL. The book should appeal to those interested in sugar production, Papua New Guinea, economic development, and how history is made. It is highly recommended.

Making Place: State Projects, Globalisation and Local Responses in China. Stephan Feuchtwang, ed. London: University College London Press, 2004. 214 pp.

\section{TAMARA JACKA}

The Australian National University

"Place making" has been a central concern in recent social theorizing, especially in anthropology and human geography. However, it has received relatively little attention in studies of China. This book, therefore, makes a very welcome addition, both to China studies and to social theorizing in general.

The book consists of an introduction, eight chapters, and an afterword, written by a mix of junior and senior anthropologists from the United Kingdom, North America, Australia, and China.

The Introduction, "Theorising Place" by Stephan Feuchtwang, introduces and explains the theme of the book-"territorial place-making"-and positions it with re- spect to recent debates over "space" versus "place," modernity, postmodernity, globalization, and state and capitalist territorialization and deterritorialization. This is a densely theoretical chapter, and it is dizzying to join Feuchtwang as he flies from recent anthropological studies of place to Deleuze and Guattari on capitalism and deterritorialization and Appadurai on globalization and "ethnoscapes" to discussions of cosmologies and specifically of Chinese fengshui to Edward Casey's phenomenology of place. All the same, it is a fascinating flight. Feuchtwang makes a valiant effort to draw China into theory and theory into China studies and presents some important arguments. In particular, against Hardt and Negri, and others, he argues that territorial place making is not entirely determined by global capitalism but is "a negotiation with and a reappropriation of state and capitalist territorialisations ... moved and accomplished by other ways of making place than those of global capitalism or its state formations" (pp. 14-15).

The quality of the core chapters is variable, as is the degree with which they take up the themes iterated in the introduction. The selection of chapters also strikes me as a little peculiar. In particular, "Mapping 'Chaos': The Dong Xi Fo Feuds of Quanzhou, 1644-1839," by Wang Mingming, is the only chapter to focus on place making before the 20th century; this chapter links only poorly with Feuchtwang's and other contributors' concerns about place. It also struck me as odd, in a collection that ranges so widely across both time and space, to include two chapters on the same placeTsuen Wan in Hong Kong.

Nevertheless, this volume includes several excellent chapters. I found Chapters 5-8 particularly well written and worthwhile. Elizabeth Lominska Johnson presents a fascinating discussion of place making in Tsuen Wan, Hong Kong. Johnson shows that today, despite large-scale immigration and industrialization, the "natives" - that is, those people whose ancestors owned or used land in Tsuen Wan when the British government took control of the New Territories-still maintain and express territorial rights and responsibilities through ritual and political activities focused around the Rural Committee, the Tian Hou temple, earth god shrines, and ancestral halls.

Zhao Bingxiang makes the case that places are made in terms of differentiation with other places, and shows how this has occurred historically in one village in southeastern Shandong and a second village in western Heilongjiang, to which inhabitants of the first village had migrated.

Nicholas Tapp ruminates over whether or not people who have traditionally been shifting cultivators, such as the Hmong, have a different sense of place to that of more settled peoples. But Tapp answers his own question in the negative, suggesting that "in general they have just as strong attachments to homes and local places as anybody else, despite having to move about" (p. 136).

Mary Rack, examines the multiple and changing nature of place making as it occurs around temples in west Hunan. Rack shows that people in west Hunan commonly show little sense of attachment or belonging to the land. As a 
result of a series of in-migrations over time, no one describes west Hunan as their ancestral home, and most express fear or even hatred of the terrain. Temple worship and festivals are a means of creating a sense of place in this wild terrain but, Rack shows, different people draw quite different senses of place from the same festival.

This volume is full of questions and ideas. It does not address everything, of course. For example, none of the authors examine in any detail the effects of class or gender on senses of place within a community-that will have to be taken up in another volume in the future. All in all, though, this book provides plenty of food for thought for scholars and postgraduate students in China studies and anthropology.

The School of the Americas: Military Training and Political Violence in the Americas. Lesley Gill. Durham, NC. Duke University Press, 2004. 281 pp.

\section{ADAM SGRENCI}

San Francisco State University

\section{ROGER BURBACH}

University of California, Berkeley

For Fernand Braudel, history is the presentation of a "succession of landscapes" composed of two levels of human existence: (1) the realm of major historical events and (2) "the ground floor" that lays in "images of daily life" (1981:559). According to Braudel, those that present history must reveal the dialectical interplay between the upper and lower levels.

Lesley Gill's The School of the Americas takes us on a journey into these two realms. In level one of human existence, Gill situates the discussion in a geopolitical context-from the Monroe Doctrine and My Lai to the Cold War and the post-September 11 "War on Terror." But it is in Braudel's second level that her argument gains real lucidity. Perspectives are drawn from three distinct groups: the military officials and the soldiers, the repressed peasant coca growers in Bolivia and Colombia, and the U.S. activists who have mobilized for more than a decade to shut down the school.

These everyday images on the "ground floor" include testimonies from 11 top officials from the School of the Americas (SOA) including six former commandants, 35 graduates, and ten major leaders of the anti-SOA campaign known as SOA Watch. Gill goes beyond previous analysis. Most literature on the subject of military testimonials find their defense of the institution as simple dissembling"free-floating bureaucratic responsibility that is never assigned to specific individuals" (p. 56).

Not so, argues Gill. The dismissal as such is much too simplistic. It "misses the way that particular ideologies are shaped in specific social and institutional contexts and become part of deeply held personal feelings" (p. 56). Not only did Gill observe classes at Fort Benning, Georgia, where the school, now called the Western Hemisphere Institute for Security Cooperation (WHINSEC), is currently located; she was also the only scholar or reporter permitted to attend closed-door meetings in which military officials discussed the ways in which a cosmetic change would improve the school's image in the public eye (p. 225).

Many critiques of U.S. imperialism attribute its efforts to that of a unilateral actor. Contrary to this general claim, Gill argues that "[U.S.] dominance in the aftermath of World War II was based less on unilateralism-'telling them that something is going to happen' - than on a complex process of collusion in which U.S. military power was effectively joined with the indigenous military establishments of Latin America" (p. 59). The United States has acknowledged the relative decline of its economic dominance since World War II and knows that only by convincing others to spread the word of its military preeminence will it hold on to its power. This is the relevance of the School of the Americas-a factory of messengers and enforcers of ideology.

And it is an ideology that depends on impunity. The attention she draws to this concept is quite central to the salience of her case. Gill divides this discussion into two parts: the first on how the School of the Americas deals with trainees on the subject of human rights, and the second on how the dynamics of impunity affect the relationship between state violence and social fragmentation in two Andean communities. Gill explains that impunity places peasant families "outside the law" and denies them a political voice as well as aggravating their poverty (p. 167). Because of this, the state is forced to control the ensuing chaos and resorts to even further repression. She also claims that the impunity of state-sponsored terror "[imposes] a wall of silence between people, and [feeds] on rumor and speculation. Speaking out becomes impossible" (p. 189).

Impunity is what triggered the campaign to shut down the SOA and Gill gives us an honest account of its successes, failures, and potential. Although the 1989 Jesuit murders in El Salvador had a profound impact on the religious organizers of the anti-SOA movement, "righteous anger ... was not enough to generate a grassroots movement that required strategy and an organization" (p. 200). Gill salutes Braudel when she refers to the Central America solidarity movement of the 1980s that was preserved by an "enduring activist subculture" and served as an "inspirational bridge" to the contemporary campaign to close the SOA. This "social energy" has existed in the past, continues to do so in the present, and is what will build a peaceful future.

\section{REFERENCE CITED}

Braudel, Fernand

1981 Civilization and Capitalism. New York: Harper and Row.

The Spectacular City: Violence and Performance in Urban Bolivia. Daniel M. Goldstein. Durham, NC: Duke University Press, 2004. 275 pp.

\section{MARK GOODALE}

George Mason University

Daniel Goldstein's recent study of "dramas of citizenship" (pp. 5, 19) in periurban Bolivia makes important contributions across a range of ethnographic and theoretical 
issues. In locating the spectacle of public lynchings-or attempted lynchings - in the same discursive and performative space as an annual street carnival and festival in one of Cochabamba's barrios, Villa Pagador, Goldstein employs a series of innovative arguments for understanding the nature of violence, marginality, and the distribution of power within insecure states. Many of us may have assumed that lynchings and other expressions of "community justice" in Bolivia represented a set of social and political dynamics related to endemic poverty, racial marginalization, and the general failure of the state and its instrumentalities. However, Goldstein argues that one must view lynchings instead as one among a group of public dramas that serve to enact group identity through the politicization of what is in Bolivia, as elsewhere, a contested public sphere. Through his analysis of lynchings and fiestas, two seemingly distinct "vivid, visual displays of collective identity" (p. 3), it becomes clear why they must be reconceptualized:

both represented appropriations of cultural or legal domains typically designated as arenas of state control; both revealed the deep tensions and antagonisms underlying the ordinarily placid façade of daily life. And significantly, both events expressed a demand for inclusion in the national bodies politic and social by a group of people who had been systematically excluded from full membership in the Bolivian nation. [pp. 3-4]

In reconfiguring our understanding of what appear, from the outside, to be simply senseless and chaotic acts of community outrage directed against the only available targetscommunity members themselves-Goldstein is forced to walk a number of very thin lines. This has also been true of other anthropologists who have engaged in counteranalyses of performative violence in urban landscapes of fearfrom the shantytowns of South Africa to the favelas of São Paolo and the streets of New York's El Barrio. It would have been all too easy to adopt a critical ethical stance in relation to both the lynchers and the local coterie of corrupt police officers and governmental officials, whose systematic detachment from Cochabamba's marginal barrios has rendered areas like Villa Pagador virtual zones of state exclusion. Goldstein recognizes that the actual events, which eventually led him to rethink prevailing discourses of violence, evoked a complex set of analytical, emotional, and methodological responses and concerns: the fear of exploiting either victims and victimizers (or both); the pressure of countervailing expectations that he would either condemn, or help to justify, the violence he witnesses; and the everpresent possibility of engaged intervention. Moreover, his book raises another, more basic question for a postpositivist ethnography of violence: Where the destruction of bodies is primarily a sociopolitical act, how can a meaningful interpretation be derived that is neither unduly particularistic nor dependent on liberal-even if localized-narratives of "justice" or "due process?" Goldstein responds to these challenges by adopting a position of reflexive neutrality. His reconceptualization of "vigilante justice" as spectacle is meant, in part, to refract the various ethical and methodological dilemmas rather than definitively resolving them.
Although it does not detract from the book's accomplishments, which are considerable, I have one minor critique. I am not entirely convinced by Goldstein's inversion of Foucault's analysis of "the public execution as a form of political ritual" (p. 215). In Goldstein's formulation, if executions "provided the sovereign with an instrument for the public display of his power, lynching in Cochabamba ... is an instrument that marginalized groups can employ to demonstrate... their powerlessness" (p. 216). (This is actually a double inversion-state : power :: the people : powerlessness.) But because the function of executions is to dramatize the sovereign's power as part of a wider repertoire of "arts of governmentality" (pp. 30, 89), it is difficult to reenvision the use of lynchings in these terms, because the absence of power means the use of lynching can never be "theater" that "engrave[s] upon the observer's memory a vivid image of the [people's] might" (p. 216). Perhaps a better inversion would have been through Habermas and not Foucault. As Goldstein's book demonstrates, spectacular performance reflects what could be understood as "communicative irrationality" - $\mathbf{a}$ dialogic and intersubjective act that legitimates the dramatic, the violent, and the potentially revolutionary.

Reckoning with Homelessness. Kim Hopper. Ithaca, NY: Cornell University Press, 2003, 271 pp.

\section{DAVID I. BERISS}

University of New Orleans

Homelessness appeared on the scene as a distinct social problem at the end of the 1970s, along with neoliberalism, Ronald Reagan, and the decline of the welfare state. Before that there were poor people and some of them did not have places to live, but their situation was not understood as homelessness, at least not in the same way we understand it now. Instead, it was an extension of poverty, a result of alcoholism, or even a lifestyle choice. In Reckoning with Homelessness, Kim Hopper provides a very personal history of how the United States created this particular social problem.

Hopper has been studying homelessness and working with homeless people since the 1970s. Most of his research has been conducted in New York City, although he is clearly familiar with work that has been done elsewhere as well. In addition to field research, Hopper has been an activist, helping to found a variety of advocacy and service organizations, including the National Coalition for the Homeless (he was a board member for that organization when I worked there in the mid-1990s). His long experience in this field allows him to combine insights into the survival strategies of homeless people with a clear understanding of the way policy makers think. This makes for a rather unique book.

Hopper begins by placing homelessness in a broad social and political framework. His objective is less to provide an ethnographic account of the experiences of homeless people than to ask why Americans think-and act-about homelessness the way they do. One key concept he uses to 
frame his approach is "abeyance," which Hopper uses to refer to the way industrialized societies address the existence of "surplus" people. Rather than ask whether or not homelessness will be solved, Hopper argues that key questions should center on what counts as an adequate solution to the problem at any given moment (p. 19). By framing the question in this manner, Hopper is able to direct attention to the broader ethnographic context in which homelessness exists. He also draws on "liminality," a concept more familiar to anthropologists, to frame his arguments. He suggests that the institutionalization of homelessness as both a social problem and as an object of a service industry indicates that some forms of liminality have become permanent in U.S. society.

Four chapters form the core of the book. In those chapters, Hopper draws on his earlier research to outline the contours of homelessness in New York. His focus is not comprehensive-he focuses almost entirely on men, for instance-but he uses his data less to illuminate the world of homeless people than to show how research and public debate have framed homelessness in the United States. He revisits, for instance, a study he conducted with Ellen Baxter between 1979 and 1982 on homeless men in New York. Rather than simply review his older work, however, Hopper indicates what had and had not changed with the development of homelessness as a visible social problem during the same period. In another chapter, Hopper reviews a study he conducted of homeless people living in an airport terminal. This provides a sharp contrast with the kinds of official shelter spaces used by the city and further insights into what makes an existence liminal in U.S. society. The next chapter examines the difficulties involved in attempts to enumerate the homeless population. Hopper points out that the way in which the question of how many homeless people there are is framed reflects already existing evaluative concepts, which are, in turn, reflected in public policy. Hopper also devotes a chapter to the growth of homelessness among African American men in New York. He argues that political-economic changes in New York, along with changing kinship practices and reduced government support, have all combined to make at least temporary homelessness much more common for young African American men in recent decades.

The last section of the book is devoted to an analysis of advocacy on behalf of homeless people. Although he points to some of the policy victories won over the years, he is deeply pessimistic about the possibility of changing some of the underlying cultural assumptions that prevent problems of poverty and homelessness from being resolved. If there is a contribution that an engaged anthropology can make, Hopper argues, it is in calling attention to the concepts that frame these broader issues. Although understanding the lives of poor people is a useful project, Hopper directs our attention to the society that makes people poor and homeless in the first place.

This is an elegantly written and passionate book. It provides an excellent example of the kind of engaged, public anthropology that many anthropologists have been calling for in recent years. I think, however, that it will be best appreciated by other anthropologists and by people who are already familiar with the history of social policy. Undergraduates unfamiliar with that history may have some difficulty with Hopper's assumptions; although the book provides quite a comprehensive set of references to the literature, it seems to assume a familiarity with debates about poverty in the United States that students are unlikely to possess. For people already familiar with that material, this book is essential reading.

Casta Painting. Ilona Katzew. New Haven, CT: Yale University Press, 2004. 256 pp.

\section{JOAN DELPLATO}

Simon's Rock College of Bard

Ilona Katzew examines the phenomenon of 18th-century Mexican casta painting-portraits of racially mixed families depicting a pair of parents and at least one child-produced in an urban colonial social system undergoing rapid material growth and changing ideologies of race and power. Throughout the century, over 100 sets of paintings were made for the consumption of elites in Peninsular Spain who harbored "anxiety" over the New World's readiness to blend the races: African, Spanish, and Indian. The book investigates how miscegenation contributed to the construction of a colonial subjectivity rooted in race and social status. The focus of the book is a shared concern of the disciplines of anthropology and art history: the critique of visual representation.

Katzew admirably argues that casta painting served a paradoxical function. On the one hand, it assured Spanish art buyers that their worries about the perceived chaos of the social structure of New Spain were unfounded, that blending was occurring but in finite permutations, as indicated by each painting's formulaic inscription that spelled out the family's mixed racial identity (e.g., "Spaniard and Indian Produce Mestizo"), and that Spanish-white culture was the reference point and ultimately the most desirable position. On the other hand, casta painting could be seen to celebrate mestizo cultures by depicting regional peoples, legitimizing mixed unions, and presenting their divergence from white culture as natural occurrences within Mexico's population; like exotic flora and fauna the pictures could be seen as an expression of the plenitude and variety ordained by God.

Katzew offers intriguing new research throughout the book, exploring contemporaneous accounts of color hierarchies to develop racial ideologies of the sistema de castas. For example, she uncovers the phenomenon of "blood mending," in which Indian or black blood was thought to be obliterated when, over the course of four generations, it could be returned to whiteness. She is convincing in her argument that racial concerns were pressing; she offers the first scholarly analysis of Mexico's earliest satirist, Pedro Anselmo Chreslos Jache who, in writing the Decrees of the 
Baratillo of Mexico, inverts the racial hierarchy so as to criticize it. But she is less interested in applying the subtle contents of such thinkers about race to elucidate particular casta paintings, content to let them stand as "context." Indeed, the major flaw of the book is that at the very places where a large corpus of research is expected to be brought to bear on the casta paintings, it does not appear.

Still, an especially satisfying exploration in the book is her reading of seemingly innocuous pictures of casta mothers pacifically nursing their children and accompanied by attentive fathers. Her research reveals an objection among Spanish writers to the practice of hiring mulattas as wetnurses, thought to corrupt lighter-skinned children. Thus, she interprets paintings of nursing mothers as the triumph of male control over the female body, a position that was in keeping with racial and gender ideals popular with officials in Spain as part of an ideologically motivated reeducation program. One wishes for more in-depth study of other narrative or iconographical details that could yield similarly rich results.

In an appealing assertion that colonial culture was no mere European derivative, Katzew claims that the genre of casta painting had no equivalent in European art. Still, she traces the origins of casta painting to a German 17thcentury book on Chinese costumes, which Manuel Arellano, the earliest Mexican casta painter, had in his library. Her case is intriguing; however, casta painting's origins could also be considered from the users' viewpoint as much as the creator's. With this in mind, two suggestions are offered: First, rather than any single book in particular, might its sources be a whole genre of European travel books describing marriage customs, mores, and native dress of exotic Others from many geographical locales? Such a focus could serve Katzew's ends, as she claims to want to downplay the art historical convention of considering the artist's oeuvre and emphasize more the works' social and political contexts. Second, even the earliest set of casta paintings she illustrates could be seen as ethnicized variations on the iconography of the Holy Family or Madonna and Child, two of the most popular themes in all of European religious painting, which parallel the rise of secular family portraits. Acknowledging this could strengthen her political perspective by implying that colonized peoples rework "influence" of the dominant culture in creative and resistant ways.

The book was the catalog to an exhibition of casta painting held at the Los Angeles County Museum of Art in the spring and summer of 2004. Its format is lavish. By the end of the first chapter alone (37 pages), there are 39 color plates, eight color details, and 23 black- and- white images. Was this "picture-stuffing" an editorial gamble to merge a coffee-table format with a scholarly study in hopes of garnering interest of the Chicano/a, African American, and Latino/a markets of Southern California, as well as more generalized cultural interest in race studies? Such a design could offer the art historian a golden opportunity to produce a book that is both academically rigorous and attractive to a wide clientele, including presumably descendants of those very groups whose identities were being constructed in casta painting. However, reading the text systematically alongside the many pictures in Katzew's book is distracting, at times confusing. Plates are left undifferentiated from each other in significant enough ways to warrant their inclusion. Illustrations of baffling images can be far removed from their explanations, with no indexing system to facilitate locating them. For example, disturbing images in chapter one showing scenes of domestic violence are not addressed until page 114, in which we finally learn that physically feuding spouses were thought to be the result of the mismatching of races or overindulgence in intoxicating pulque. Also, captions are placed so as to make identification of plates frustrating. An appendix would help readers unfamiliar with racial terms, slippery as they may have been in their usage-for example, coyote, grifo, tente en el aire, lobo, and campujo.

Had Katzew's book considered fewer examples of casta paintings, and had she analyzed more closely their individual relationships to the documentation she has so admirably unearthed, the book could have fulfilled even more effectively the promise of elucidating the complexities of her utterly original and supremely important topic-race, art, and power in the New World.

Words and Stones: The Politics of Language and Identity in Israel. Daniel Lefkowitz. New York: Oxford University Press, 2004. 316 pp.

\section{REBECCA L. STEIN}

Duke University

Daniel Lefkowitz's Words and Stones: The Politics of Language and Identity in Israel employs ethnographic and sociolinguistic analysis to explore matters of Israeli identity and language politics in a variety of communities within Israel's 1967 borders. The scope of this book is relatively broad; it is, at once, a study of the ways Mizrahi, Askhenazi, and Palestinian Israelis constitute themselves, and are constituted, by language-and what language usage tells us about their complex social locations within the nation-state; of the politics of representation within dominant Israeli media (namely, the Hebrew press); and of the social fabric of the socalled mixed city of Haifa, where much of the ethnography is conducted. It is also an attempt to advance a methodological argument about the value of a diversified sociolinguistic approach, "integrating quantitative sociolinguistic analyses of linguistic form with qualitative interpretation of speaking practices" (p. 269) as a means of understanding the complex relationship between "language and society" in early 1990s Israel.

For this reader, it was Lefkowitz's ethnographic work in and on Haifa that yielded some of the richest material. It is precisely the fiction of the "mixed city" that is at issue for Lefkowitz. For despite the city's varied demographicshome to working- and middle-class Mizrahim, Ashkenazi 
Jews (typically of a higher-class position and symbolic location within the nation-state), and Palestinians with Israeli citizenship (the latter, what remains of the much larger Palestinian population that lived in Haifa prior to their flight during the course of the 1948-49 war)-neither spatial nor social integration is prevalent, certainly not within the city's residential districts. Interviews conducted within these various communities usefully refute the popular Israeli myth of urban coexistence, even as they illustrate the complexity of the city and its multiple histories, the ways spaces are used and delineated by ethnicity and race, and the rather limited forms that interaction takes between and within the city's sectors.

Although Lefkowitz's ethnographic insights on matters of race and ethnicity are not new, they are crucial: namely, that although Jewish Israelis (particularly, I would argue, elite Jews of European descent) are vividly attuned to the social fault lines separating Jews from Palestinians within the nation-state, they are remarkably resistant to acknowledging parallel divisions within Jewish society (in terms of class, ethnoracial history and culture, language usage, and space and spatial usage). As Lefkowitz argues, "dominant Israeli discourse simultaneously dichotomizes (exaggerates) Arab/Jewish difference while it erases (minimizes) Jewish/Jewish difference" (p. 98). Echoing U.S. mythologies about whites and whiteness, such discourse marks Jews of European descent as without ethnicity (cast, as they are, as "normative" Israeli subjects), whereas Mizrahi Jews are marked as "ethnic" and, in turn, lacking in normativity. As Lefkowitz usefully notes, "race" is infrequently remarked on within dominant Israeli discourses about the nation-state, this being yet another index of their highly selective attention to modalities of intranational difference. The book's other strengths include its discussion of Hebrew language instruction and acquisition within various communities, the social politics of intonation and pharyngeal variables in Hebrew usage, and ethnographic attention to the histories and memories of interviewees (including personal histories of the 1948-49 experience among Palestinian interviewees, and of Mizrahi immigration to Israel).

And yet, despite such strengths, this reader found the monograph problematic in crucial ways. The book's breadth is something of a liability. Sutured-sometimes loosely-by the rubric of sociolinguistic analysis, it attempts to tackle far too many themes and historical conjunctures; what results is a set of rapid, sweeping histories (e.g., the legacy of the Jewish victim complex or the history of Jewish-Palestinian violence and Israeli warfare) that, in their brevity and prevalence, cannot but fail to be partial. Given short shrift, in the process, are the historical particulars of language usage and identity politics at the time of the ethnographic project itself-namely, the early 1990s. Not all the phenomena that Lebowitz describes are particular to this period (for Mizrahi and Palestinian subalternity within the state, and their linguistic corollaries, both precede and exceed this historical moment), yet the political landscape of the 1990s would change dramatically by the decade's end.
By the turn of the 21st century, language and identity politics in Israel had shifted considerably as a result of radical demographic and cultural changes within the borders of the nation-state, including the following: the massive influx of foreign workers from the "third world" (imported, by the state, to replace the blue-collar Palestinian workforce from the West Bank and Gaza Strip, deemed a political liability); the growing visibility of Mizrahi ethnoracial histories and political demands, evidenced by the rise in prominence of the Shas party; and the radicalization of the internal Palestinian population, as exemplified by their expressions of solidarity with the Al Aqsa Intifada. More attention to the ways that language and identity articulate through the particulars of their historical moments, and through those of the Haifa case, would have made for a richer investigation. Other shortcomings in the monograph include (1) the preponderance of self-reflexive ethnography (concerning the status of the Jewish American researcher) without adequate discussion of the utility of such a narrative practice within a study of Israeli identity; (2) the relative inattention to the politics of language usage within the ethnographic interviews (most, it seems, were conducted in Hebrew, typically by Jewish Israeli research assistants, even among Palestinian populations for whom Hebrew is a second languageand a politically charged one, as the monograph suggests); (3) thin discussion of questions of gender as they articulate with ethnonational, religious, and racial identity; and (4) truncated discussion of the relationship between the highly divergent intellectual traditions of language and discourse analysis on which the monograph draws (e.g., those of qualitative linguistics and Foucaultian analysis, respectively).

For scholars interested in contemporary Israeli cultural and linguistic politics, and for those concerned with the relationship between language and identity more generally, this is a useful volume. Indeed, despite its shortcomings, it represents one of the few English-language studies on the social politics of language in the contemporary Israeli context. Lebowitz's insights on matters of ethnoracial identity in Israel are sharp and important, powerfully exposing the sociolinguistic terms of power and powerlessness within Israel and unseating the dominant Israeli fiction of "the [singular] Jewish people."

Middle Eastern Lives in America. Amir Marvasti and Karyn D. McKinney. Lanham, MD: Rowman and Littlefield. $171 \mathrm{pp}$.

\section{KHALED FURANI}

Visiting Scholar, Columbia University.

With a lucid yet at times awkward and imprecise vocabulary, sociologists Amir Marvasti and Karyn D. McKinney focus on discrimination against peoples from the Middle East in the United States. Straddling between analysis and prognosis of a social "ill," they argue that racial and ethnic discrimination against this population is real. In 
normal circumstances, their argument would seem superfluous, but in a public domain that targets the faculty of discerning the real from the unreal, or liberation from occupation, their exercise is not so superfluous after all.

Nearly two decades after Writing Culture (1986), some anthropologists may find it irksome that the authors apologetically explicate their resort to "experiential" and "formalized" data, by which they mean biographical materials and recorded interviews, respectively. These are the sources that Marvasti and McKinney largely reserve for the second part of the book (five chapters) devoted to "daily lives." The quantitative data can be found in the first part of the book (three chapters) on "social forces."

As if "social forces" and "daily lives" exclude each other, in the first section of the book Marvasti and McKinney present historical and sociological information about Middle Eastern Americans-mainly in the form of statistics, which gives their presentation a quality of profiling, rather than narrating the lives of Middle Eastern North Americans. This sense of profiling is intensified when one reads the authors' presentation of categories of Middle Eastern lives, including education, income, and political involvement, the quantitative content of which they extend to nonArab groups composing "the Middle Eastern community." Here, another tension inhabits their book: Who is "Middle Eastern?"

The authors invoke "Middle Easterners" when, in fact, they generally mean Arabs and Muslims. Otherwise Israelis, for example, should have been included in their sample. Oddly enough, their sample includes six Pakistanis, but no Indians. The mere three paragraphs they dedicate to answer the question "who is Middle Eastern American?" stands as a regrettable lack of a detailed inquiry into this intractable colonial carving called "the Middle East." It is not clear how making sense of racial inequality helps with fighting it (p. 163), yet what is clear is that it makes no sense to talk about empowerment when the very name one employs to identify one's subjects remains unexamined.

The second and third chapters focus on the question of Islam's link to terrorism (terrorism itself is not the subject of equal elaboration in this book). The authors insightfully remark that Islam is invoked when the perpetrators of violence are Muslims in ways that Christianity is not when the perpetrators are whites or Christians. They demonstrate how the violence of white North Americans is presented in the media as an isolated aberration of "psychologically imbalanced individuals" (pp. 73-74). The authors unconvincingly attribute the endemic misunderstanding of Islam to the absence of "contextual" details and a "complex" debate about it. Seeing the misunderstanding of Islam as essentially a cognitive or analytical failure, they assert that Islam is too diverse. That it surely is, but more than two decades after Said's Orientalism, I suspect, it is more useful to inquire not into how Islam's diversity defies essentialism but, rather, how, in spite of its diversity, demonizing Muslims and Arabs is so prevalent.
In the second part of the book containing the bulk of the study's interviews, the authors convey highly engaging reflections and testimonies by Muslim-Arab Americans on how they live in and respond to a society that misunderstands and mistrusts them. More specifically, the authors examine what they call ethnogenesis. Through this concept, they refer to a gemeinschaft of sorts whereby peoples from the Middle East presumably forge a common panethnic identity that transcends their differences. Yet out of the eight respondents in that chapter, only two invoke the Middle East as an index of a collective identity and none identify as such. In fact, the only two instances of coalition formation the authors cite were on religious, not ethnic, grounds. In the first instance, they refer to a woman who is active in the Council on American Islamic Relations, which by definition works on cultivating a religious not national identity (p. 146). And the second instance has to do with a man joining the ACLU for its defense of Muslim, not Middle Eastern, causes (p. 159). Therefore, the existence of ethnogensis, appears more as a prescription of something yet to exist and hardly as probing of people's realities as the authors would have us believe (p. 150).

Because of the authors' concern with the advancement of a more inclusive U.S. democratic system, their book could benefit anyone interested in a liberal Durkheimian critique of domestic imperial excesses. Finally, a work that explicitly states that Arabs speak Arabic and Iranians speak Farsi obviously aims to reach readers who know little to nothing about the Middle East.

Cattle Bring Us to Our Enemies: Turkana Ecology, Politics, and Raiding in a Disequilibrium System. J. Terrence McCabe. Ann Arbor: University of Michigan Press, 2004. 299 pp.

\section{CAROLYN K. LESOROGOL}

Washington University

In Cattle Bring Us to Our Enemies, Terrence McCabe provides a convincing empirical demonstration of the "new thinking" in ecology, which posits that some ecosystems are in disequilibrium. Through his detailed analysis of Turkana herding strategies, McCabe shows how these Kenyan pastoralists respond to their arid environment in ways predicted by disequilibrium theory: frequent and highly variable migrations, opportunistic herding strategies, occasional dependence on external resources, dramatic fluctuations of livestock numbers, and loose coupling of livestock with forage resources. In his recognition of the multiple forces and factors implicated in Turkana survival strategies, McCabe calls for a political ecology that considers both politics and ecology, challenging both narrowly ecological and wholly political approaches.

The book is based on McCabe's long-term research (1980-96) among a section of Turkana pastoralists, much of which was conducted under the auspices of the South Turkana Ecosystem Project (STEP). Throughout the book, 
he highlights key research findings of the STEP, especially regarding the development of disequilibrium theory, which constitutes a serious challenge to conventional understandings of ecosystems as self-regulating equilibrium systems. The literature review (Chapter 2) delineates the links between equilibrium thinking in ecology and ecological thinking in cultural anthropology, especially the rise of cultural ecology in the mid-1900s. He documents the challenges to these approaches manifested in disequilibrium theory in ecology and behavioral and political ecology in anthropology, including the role of methodological individualism and rational choice theory in behavioral ecology. McCabe takes an intermediate stance, claiming that "the theoretical focus of this book can be seen as ... the integration of individual-and systems-level analysis" (p. 31). He does provide multiple levels of analysis including individual decision making, group-level herding patterns, and national and international policies that affect Turkana pastoralists. The analyses of decision-making patterns among four herding families (particularly the male heads of these families), however, are the core of the book and, in my view, the most effective in making his case. His analysis of decision making seems closer to rational choice (which can also accommodate exogenous factors) than he claims.

Following the literature review (which includes a nice discussion of theories of violence in anthropology) and background material on the Turkana and their environment in Part 1, Parts 2 and 3 present a detailed analysis of herding decision making among four families that McCabe followed from 1980-96. Narrative accounts of movements and their rationales are followed by a quantitative analysis of reasons for movement, frequencies, and durations. The season by season accounting of movements, although at times tedious, clearly shows the influence of environmental factors and (in)security in the patterns of movement of the herders. Herding strategies are also determined by individual personalities (more aggressive or more conservative) and by individual circumstances (size of the herd, availability of labor, and trustworthiness of herding labor). Thus, although the environment (both natural and political) clearly puts constraints on individuals and broadly patterns their movements (as further demonstrated in the group-level analysis of Part 4), there is still scope for individual choice and variation-something not well captured in disequilibrium theory. McCabe also discusses the effects of marriage decisions and social reciprocity, again using the four families as examples, and how these social goals intertwine with that of increasing livestock numbers for survival. It is difficult to evaluate how generalizable the family growth patterns observed here are, and the discussion would have been strengthened by some theorizing of the operation of the social institutions (e.g., marriage, reciprocity, and management of common property) in general.

The book is weaker in its conclusions about the implications of disequilibrium thinking for policies toward pastoralists. McCabe rightly calls for East African governments to provide security for pastoralists, but he does not analyze why such calls have not been effective to date. He does not comment on recent studies of pastoral land tenure or conflict mitigation programs conducted in Kenya, nor on the ongoing constitutional drafting process in which land rights are likely to be institutionalized. The impact of the market economy is downplayed. Although it may not have been critical to the four families studied, markets are certainly an important force for the Turkana, many of whom have left the district to seek employment elsewhere. That said, this book is an important contribution to the literature on East African pastoralism and an effective demonstration of disequilibrium ecology in action.

Migration, Modernity and Social Transformation in South Asia. Filippo Osella and Katy Gardner, eds. Thousand Oaks, CA: Sage Publications, 2004. 380 pp.

\section{KAREN LEONARD}

University of California, Irvine

These 13 ethnographic studies of international and intranational migration in South Asia look at both the receiving and sending communities and are framed by a useful introduction by Katy Gardner and Filipppo Osella that reviews the theoretical literature and compares the chapters along several dimensions. The book calls attention to intranational migration and the consequences of migration for the migrants' home communities, redressing the greater attention often given to international migration and questioning simplistic notions of cultural hybridity versus essentialism, cosmopolitanism, postnationality, and the like. The chapters address these theoretical issues vigorously. Another strength is the historical depth and cross-referencing characteristic of the studies (some chapters were given in 2001 at a University of Sussex conference and those plus others were published in Contributions to Indian Sociology in 2003).

Because the outstanding feature of the volume is the thorough ethnographic and historical research conducted by the contributors, a necessarily brief summary follows. Jonathan Spencer reviews population movements in Sri Lanka to show management by colonial officials and an evolving postcolonial rhetoric of national purity for mass mobilization; here, the politics of movement and violence and the history of border transgressions and hybridity questions current notions of transnationalism, globalization, and a "post-national" order. Roger Ballard looks at Pakistani migrants from Mirpur in Britain, focusing on this district to show that substantial remittances over several decades have not produced sustainable economic development there. Ballard argues that both economic and social transformations have been seriously constrained, not through the failure of Mirpuri entrepreneurship but because the Pakistani state has failed to provide infrastructural transformations. Francis Watkins's study of poor Pakhtuns from Kohery village in northern Pakistan migrating to the Gulf states finds that money earned abroad is well spent to build stronger families and kin ties at home and that a "more 
international understanding of Islam" (p. 61) has added a spiritual dimension to traditional Pakhtun notions of honor and influence. Edward Simpson also takes up Islamic reform, adding social and religious practices (rival versions of Islamic orthodoxy) to gifts and ideas when considering the fruits of migrations. Simpson attributes social differentiation among Sunni Muslim ship owners, sailors, and their kin in the town of Mandvi and the village of Salaya in Kachchh, Gujarat, to earlier migrations and relates the exchange of gifts and commodities to Islamic reform and the relative moral qualities attributed to different kinds of exchanges. Filippo and Caroline Osella show how migration from Kerala to the Gulf has produced changes in the Hindu kuthiyottam ritual (human blood sacrifice), reflecting upwardly mobile people and innovative forms and senses of religiosity. C. Y. Thangarajah focuses on female Muslim migrants from eastern Sri Lanka to the Middle East and their reconfiguration of everyday practices within a more panIslamic framework, seeing this as enabling the women to expand their rights and opportunities. Maya Unnithan-Kumar connects poor Rajasthani women's migrations to a slum in Jaipur, India, to reproductive anxieties and outcomes, discussing both positive and negative outcomes for them. Arjan de Haan describes labor migrants in Calcutta and their encounters with modernity as structured by gender, generation, region, religion, and caste. Jonathan Parry also focuses on intranational migration to Bengal, long-distance migration to the steel town of Bhilai from other states; he found strong disinclinations to return, particularly among those best placed in the labor market, in public not private sector jobs. Geert De Neve shows that rural migrants working in the garment industry in Tirupur, Tamil Nadu, are not stereotyped as less committed or hardworking than local workers, and that, for the workers, local networks and the ambivalent nature of raised expectations shape their decisions to stay or return home. Ben Rogaly, with Daniel Coppard, Kumar Rana, Abdur Rafique, Amrita Sengupta, and Jhuma Biswas, studied interactions between those seeking seasonal agricultural work and their recruiters in West Bengal, investigating how self-identification was shifted or consolidated by migration and association with other people and places. Randall Kuhn studied rural-urban migration in Bangladesh, finding that traditional networks were enhanced to consolidate positions in cities. Finally, Vinay Gidwani and K. Sivaramakrishnan present a sophisticated case for "rural cosmopolitanism" in India, carefully disentangling cosmopolitanism from transnationalism, necessarily progressive political or cultural agendas, and modernization theory that places people, places, and cultures at different stages of development.

Several authors use the phrase culture of migration, but the book's achievement is to demonstrate the variety, complexity, and highly contextualized nature of cultures of migration. Marital, patronage, and recruitment networks at home and away are more significant than the distance traveled by migrants, it would seem, although most chapters also testify to the crucial roles played by the state or states in shaping the "modernities" differently understood and practiced in these fine case studies.

Global Prescriptions: Gendering Health and Human Rights. Rosalind Pollack Petchesky. London: Zed Books, 2003. 306 pp.

\section{KAJA FINKLER}

University of North Carolina

In her book, Rosalind Petchesky envisions, with passion, a new world order that would eliminate all injustices and inequalities and that would establish health as a human right. It would entail global governance based on having a civil society empowering women through local participatory democracy. She aspires to a globalized world that reflects popular mandates and aspirations-one in which priority will be given to health over property, and health care delivery will be equally distributed among the entire world's people.

The book describes, in rich detail, transnational women's health movements working toward advancing this agenda-the small accomplishments and the various failures of women's conferences, including those in Beijing and Cairo. Women may have become, in some measure, empowered by these efforts, however, within increasingly powerless national institutions. Globalization and privatization promoted by the World Bank, IMF, and the current U.S. administration contribute to reducing services for women and impede any success of the agenda Petchesky proposes. She describes the conferences and the attempts at implementation of women's health rights programs by women's nongovernmental organizations (NGOs) in several parts of the world-including India, South Africa, Brazil, Nigeria, and Peru, where such organizations ranged from being tolerated to neglected-providing the reader with interesting particulars. But much of the book's central thesis, frequently repeated, concerns the adverse role of global capitalism in modern society and will be familiar to readers of The Nation or The New York Review of Books.

Various significant points are raised that sometimes get lost in the minute facts presented. For example, Petchesky correctly criticizes major world institutions for their use of cost-benefit analysis to evaluate health and access to affordable health care worldwide, instead of regarding health as a universal human right. She calls attention to the vocabulary in such analyses that refers to "consumers" and "users," which becomes conflated with human rights and citizens.

Petchesky makes excellent arguments against family planning movements that stress population control, which may lead to a form of eugenics, and for programs that promote broader economic and social changes that emerge out of local initiatives and lead to declines in fertility.

After reading the book, one is left with admiration for Petchesky's exhaustive study of women's efforts the world over to achieve reproductive health rights, pursue sexual pleasure, and protect their bodily integrity. But one is also 
left with a sense of irony because the perspective presented is unrelentingly absolutist-the very approach that the author wishes to combat. For example, she argues for women's self-determination and sexual pleasure within the framework of human rights, and against rape, sterilization, and female genital surgery, or what is identified as "mutilation" (FGM). Should female genital surgery be placed in the same category as rape and sterilization? Petchesky mentions the arguments made by others that female genital alteration is accepted by a majority of women in the societies in which it is practiced. However, it is important to note that rape and sterilization are not. Should the customary practices within a culture not be treated differently from those practices that the people themselves believe are heinous? In fact, there are various studies showing that female surgeries may not be as dangerous to women's health as the Western community claims, and even anthropologists who originate from societies such as Egypt, where this procedure is practiced, take exception to Western meddling (e.g., Morsy 1990). Moreover, some have rightly suggested that there is no universal experience of sexual pleasure on which Petchesky seems to insist. Women's eroticism may not rest universally in the clitoris.

Another example of this sort of absolutism can be seen in the author's reference to motherhood. It is true that motherhood ought not be the source of identity for women. Yet the author fails to recognize that although this may be a commendable aim for women in the United States, who may have various other options, motherhood is often the sole source of identity and social status for women in developing nations. By focusing chiefly on women's reproductive health and sexual rights, paradoxically, Petchesky reinforces the view that women's identity is rooted in reproduction and motherhood. Without denying the importance of reproductive health rights for women, and the devastating effects of HIV/AIDS on women discussed in the book, much more attention must be given to the poor health of women in developing nations, which is linked to abysmal public health conditions, poor diet, ethnic wars, conflicts, and anguished social relations, all of which have deep historical roots. Although I am an admirer of some of Petchesky's previous work, her arguments in this book in support of women's reproductive health rights and sexual pleasure lack sufficient contextual analysis and seem reductive rather than finely tuned.

Because the book details the activities of women's organizations and responses by world bodies in the latter part of the 20th century, it is an important document for historians of feminism. It is also recommended to all scholars and readers concerned with women's reproductive health and how it is impeded by current globalization and privatization processes. The book will also be of interest to those concerned with bioethical issues, not only from the standpoint of the four principles promulgated in bioethics but also from a broader perspective that seeks universal justice and regards health as a right for all women and men.

\section{REFERENCE CITED}

Morsy, Soheir

1990 Safeguarding Women's Bodies: The White Man's Burden Medicalized. Medical Anthropology Quarterly 5(1):19-23.

Working Images: Visual Research and Representation in Ethnography. Sarah Pink, László Kürti, and Ana Isabel Afonso. New York: Routledge, 2004. 224 pp.

\section{S. ELIZABETH BIRD}

University of South Florida

If anyone still equates visual anthropology only with ethnographic filmmaking, this volume should finally put that notion to rest. Building on the groundwork of scholars such as Marcus Banks, Jay Ruby, Anna Grimshaw, and David MacDougall, Sarah Pink lays out the argument for visually based methods: "Our focus is on ethnography as practice," a practice that can be enriched through "visual ethnography ... informed by anthropological theory and embedded in anthropological research questions" (p. 2).

The contributors all stress that visual methods cannot replace written ethnography but may enhance it, often in surprising ways. One interesting case study is Cristina Grassemi's account of using video to acquire the "skilled vision" of dairy cattle breeders in northern Italy. Initially using the camera merely to record, she gradually realized she had to learn to achieve the breeders' "eye" for cattle, which "is appropriated and asserted through the scrutiny, exchange and evaluation of images of cattle" (p. 22). She developed her eye through filming, watching how breeders watched cows to determine their aesthetic dimensions and achieve the visual expertise that marked the masters. "I only began to 'see' when my attention was directed in a disciplined way" (p. 28).

Other studies are less innovative, but informative. Gemma Orobitg Canal originally had no intention of using visuals when working with the Pumé Indians of Venezuela. Serendipitously, she found that photo elicitation with both old and new photos produced rich narratives; later, unable to photograph nighttime ceremonies, she had informants draw both the events and, most interestingly, the spirit world into which they entered. This added a new dimension to her studies of mythical narratives; "the drawings corroborate visually the narrative structure of Pumé oral stories" (p. 44).

Another fascinating use of the visual is by coeditor Ana Isabel Afonso. She found verbal descriptions inadequate to recreate past lifeways in a rapidly changing Portuguese community, and so she enlisted an artist, who drew the scenarios described. Like an elaborate police sketch artist, he constantly adjusted his drawings of activities like smuggling, thus "recreating social memories" with the participation of community members.

Coeditor László Kürti contributes a lively study of commemorative postcards and community identity in Hungary, whereas Iain Edgar argues for "imagework," a visualization process that builds on the active imagination techniques of 
Jungian psychology. Even within an expanded definition of visual anthropology, I remain unconvinced that the technique was ethnography and not therapy.

Two chapters address ethnographic filmmaking. Paul Henley's is the only chapter that, although informed by the author's work, is not a case study but more of a discussion intended to "demonstrate what film can do for text-making anthropologists, not just as a second-order visual aid ... but as a primary medium of research" (p. 110). The other, by Victoriano Camas Baena, Ana Martinez Pérez, Rafael Munoz Sotelo, and Manuel Ortiz Mateos, describes the making of two films that sought to uncover hidden aspects of culture to make both anthropology and film "instruments of social transformation" (p. 131). They argue convincingly that there is still a role for the ethnographic filmmaker in representing marginalized cultures with the active participation of the community members-indigenous filmmaking as such is not always possible or appropriate.

Three of the final chapters, by Olivia da Silva and Pink, Pink alone, and Roderick Coover, reflect on the exciting possibilities of ethnographic visuals incorporated into new formats-interactive CDs, websites, and all forms of digital interfaces. Their case studies show the deft interweaving of visuals and words, as in Coover's account of his web-based project exploring the lives of French wine growers. Finally, Felicia Hughes-Freeland offers a thoughtful epilogue on visual anthropology and the many issues raised by innovations, from the ethics of image use to the lack of technological capabilities in many academic settings.

This book has a coherence not always apparent in edited collections, no doubt deriving from these chapters' first lives at the Working Images conference. Important themes weave through the volume. First, the value of different approaches hinges on their appropriateness for any particular project. Second, the new digital environment offers great possibilities, yet low-tech visual approaches can be just as valuable. Third, words and images must work together. This point is stressed in the most practical way; the editors produced an accompanying website that offers additional images, video clips, web links, and other resources. And finally, contemporary ethnography must be reflexive, participatory, action oriented, and driven by theory. These authors offer models of such work in a thought-provoking collection that will inspire many ethnographers to explore new methodological options.

Colormute: Race Talk Dilemmas in an American School. Mica Pollock. Princeton, NJ: Princeton University Press, 2004. 268 pp.

\section{ENOCH H. PAGE}

University of Massachusetts, Amherst

Empire by Michael Hardt and Antonio Negri describes how racism mutates. Citing Gilles Deleuze and Félix Guattari, they emphasize that "racism operates by the determination of degrees of deviance in relation to the White-man face, which endeavors to integrate nonconforming traits into increasingly eccentric and backward waves" (Hardt and Negri 2000:193).

If colormute race talk permits us to integrate nonconforming traits into retrograde patterns of dominant race thought and action, then managing race talk can circumvent an analysis of the race privilege that is the central problem.

"Colormute" policies in the bay area of California recently "ordered the district and university people to actively refuse to talk in racial terms" (2004:3) as an effort to defuse liberating race talk of the 1960s, when people insisted on racial justice. Mica Pollock theorizes how the policy creates silences and projections. The race talkers that she studied avoid public race language and privately project blame for racial patterns of school failure. They describe students whose nonconforming race traits clash with the whiteness standards governing society and the pedagogy of schooling. Students exhibiting such traits are integrated racially into schooling by means of colormute race talk in which Pollock initially shared.

Exposing her colleagues' enforced denial that race matters, Pollock opposes how denial is spoken at work. Each chapter differentiates a race-talk dilemma, indicating how faculty, staff, and district administrators negotiate colormute discussions of schooling problems. Recommendations about how to discuss each race talk dilemma are summarized. An appendix for educators is included. Her ethnographic writing, beyond reproach, shows how national racial disparities are reproduced in school. Colormute powerfully demonstrates that de-raced talk produces the race talk that obscures racial inequalities.

If Colormute aims to liberate race talk from policy control, then Pollock presumes that merely by writing this ethnography, she becomes an expert on how to manage race talk. Intended to eradicate educational inequality, her study actually may enhance inequality by skilling whites to outtalk people of color who try to address their concerns within the rules Pollock recommends. It notes but fails to analyze how colormute policies defend white privilege while demographic shifts are making people of color the national majority. For instance, her approach protects white privilege by personalizing a superintendent's angst with teachers when he expresses frustration about not seeing black and Latino students at a science fair. Rather than interrogating the structural risk that contradictorily threatens his professional and racial status when such students visibly do not appear to succeed, she theorizes merely that unskillful race talk obscures the superintendent's "racialized expectations regarding 'success' patterns" (2004:169). She fails to see the connections between his performance expectations and his own need to achieve professional success and, at the same time, sustain his own racial affiliation.

Pollock indicates that in education, adults protect their positions and racial status at certain school meetings where they all, like the ethnographer, "said nothing publicly about the racial achievement patterns I actually saw" 
(pp. 169-170). Rather than analyze educational achievement in terms of the racial inequities she observes, Pollock found district people using de-raced speech so that "even acknowledged racial inequalities would often be purposefully submerged within colormute talk" (p. 108).

Well intentioned, Pollock describes how racial privilege is reconfigured in school via private race talk but fails to analyze this discursive defense of white privilege, found even among nonwhite faculty and staff. Rather than interrogating the superintendent's unwillingness to discover how racism organizes the exclusion of students from science, Pollock proposes colormute race talk as an analytical key and presumes that speaking more skillfully will dismantle the racial dominance that sanctions colormute talk.

She watches state authorities reconstitute schools having problems in racial discipline or achievement and recognizes that racial order is reproduced, not just by talk but by tracking racialized bodies, by expecting differential abilities to reside in racialized minds, and by racially distributing dollars. Nevertheless, she relies on discourse analysis ungrounded in political economy. Her evidence shows that power is masked but does not demonstrate how those who are racially privileged benefit from its masking. Pollock suggests that we must talk race while engaging in race bending to weaken and not mute the racial categories. She observed this practice among students who, distressed by adult race politics, playfully challenge boundaries between racial categories.

Colormute exemplifies the limits of discourse analysis and shows how theoretical opportunities that otherwise might be elaborated get buried behind the postmodern façade of reformed modernity. Her book would serve best had it shown how dominant racial subjects, and their functionaries, act with interests at stake in a racial minefield that motivates them to silence the race talk of others and censure their own race talk. What Pollock implies but fails to theorize are the repercussions that the dominated fear may come from racial dominants. An excellent alternative is Breaking the Code of Good Intentions by Melanie Bush (2004), who corroborates and improves on Pollock by showing how intentions to be racially dominant are routinely masked in public by a discourse of good intentions articulated in education as "politically correct" race talk.

\section{REFERENCE CITED}

Bush, Melanie

2004 Breaking the Code of Good Intentions: Forms of Everyday Whiteness. Lanham, MD: Rowman and Littlefield.

Hardt, Michael, and Antonio Negri

2000 Empire. Cambridge, MA: Harvard University Press.

Household Decisions, Gender and Development: A Synthesis of Recent Research. Agnes R. Quisumbing, ed. Washington, DC: International Food Policy Research Institute, 2003. 274 pp.

\section{SYLVIA CHANT}

London School of Economics and Political Science
In an era in which gender and development (GAD) literature has become increasingly obfuscatory, it is refreshing to come across a volume that is empirically as well as theoretically informed, and that is distinguished by a straight, no-nonsense presentation of ideas and data.

The subject matter of the volume, namely "what goes on" within domestic units that affects women's well-being, status, and empowerment, is core to long-standing inquiry into gender in developing regions. However, although intrahousehold power relations and gender dynamics are frequently cited as major contributory factors to women's subordination, this volume takes their analysis and quantification considerably further than many other studies to date.

The book consists of a collection of analyses supported by the International Food Policy Research Institute (IFPRI), which from the mid-1990s has been running a major program on gender and household decision making. Following from a first, and more general theoretical volume to emerge from this initiative, notably Intrahousehold Resource Allocation in Developing Countries, edited by Lawrence Haddad, John Hoddinott, and Harold Alderman (1997), the present one is fundamentally case study based. Making recourse mainly to primary data generated in different localities across Africa, Asia, and Latin America, a total of 33 chapters cover indicators of gendered bargaining power within households, their impacts on gendered access to resources (including nutrition, property, social capital, legal institutions, etc.), and possible policy options to enhance women's and children's well-being - some of which have already been road tested in the field.

Although none of the country-specific chapters is more than 15 pages long, the vast majority of their authors manage to convey a creditably concise contextual introduction such that the particular thematic issues they deal with are appropriately grounded. One of my strongest feelings on reading the collection was that students would find this an excellent source of illustrative material for essays and dissertations.

Despite the comparative brevity of the case study chapters, editor Agnes Quisumbing's introductory overviews to the book as a whole, and to each section-on (1) power and resources within households; (2) agriculture and natural resources; (3) health and nutrition; (4) social capital, legal institutions, and property rights; and (5) policies and interventions-do a fantastic job of summarizing key debates and evaluating how far research to date has addressed core issues. Quisumbing's general overview, for example, entitled "What have we learned from research on intrahousehold allocation," provides a useful, readable review of models of household behavior. This covers (in brief) the unitary model associated with Gary Becker, before detailing various forms of collective model including cooperative and noncooperative variants. Despite a rather surprising omission of the work of Amartya Sen, which is often cited in the feminist literature as representing one of the first major breaks with Beckerian notions of joint utility, the 
conclusion that unitary assumptions about the household have little value in development interventions is one that will resonate with the gender and development community at large.

More interesting and informative still, however, is Quisumbing's synthesis of the main findings of the IFPRI case studies. Aside from the empirical weight they bring to the rejection of the unitary model, they also endorse a commonly found fact that despite variations in degree and kind, the distribution of power and resources within households continues to favor men everywhere in the South. The findings also emphasize the importance of directing resources to women if the members of poor households as a whole are to benefit from development interventions while also highlighting the importance of enforcing women's legal rights, not only through legislative reform but through measures to enhance their access to capability-building resources such as education and credit. With regard to policies and programs, particular attention is drawn to the need for proper grassroots evaluations of project outcomes and the importance of longer and better quality panel data to assess the impact of different types of intervention.

Household Decisions, Gender and Development will be widely appreciated among academics and policymakers alike, especially those embarking on the study of gender and household dynamics for the first time or who need a reliable and authoritative injection of information for teaching or practical purposes. Although the bibliography is by no means extensive-undoubtedly because, in part, of the minimalist nature of the contributions-most of the critical classics are included. The index is also extremely user friendly and comprehensive. The fact that the book comes with a CD-ROM should enhance its appeal even further to those new to the field.

Culture and Public Action. Vijayendra Rao and Michael Walton, eds. Stanford: Stanford University Press, 2004. 442 pp.

\section{ELIZABETH HARRISON}

University of Sussex

Culture and Public Action is an important statement of the World Bank's concern to come to grips with "culture" and to bridge an apparent gap between anthropologists and economists in efforts to alleviate poverty. It is edited by two economists, but contributors come from diverse disciplines and include a number of eminent and respected thinkers, including Amartya Sen, Arjun Appadurai, and Mary Douglas. The book is wide ranging, from largely theoretical chapters (Mary Douglas, Amartya Sen, and Lourdes Arizpe) to those that are more obviously strongly rooted in empirical examples (Carol Jenkins, Simon Harrigan, and Shelton Davis).

The introductory and concluding chapters, by the two editors, argue that a better understanding of culture can result in more effective public action-and that greater col- laboration between economists and anthropologists is part of the key to this. The point is made that, although it is accepted (presumably principally by those in the World Bank) that culture matters, there is confusion about how it matters. In setting out to correct this, the aim is to establish the positive implications of taking culture "on board in improving how culture alleviates poverty and reduces inequality in the world's less affluent countries" (p. 1). The "practical advice" that is the focus of the concluding chapter is focused on the improvement of interdisciplinary collaboration and conversation between economists and anthropologists, including the relationship between qualitative and quantitative research.

There are some very strongly argued and nuanced chapters within the collection. Those by Sen and Douglas, for example, contain important insights into definitional problems and the politics of establishing what culture means in different contexts. Equally, there are chapters that appear rooted in a view of "culture" that resonates strongly with colonial conceptions of the "customs of the locals." That by Anita Abraham and Jean Philiippe Platteau is a case in point, suggesting that current aspirations toward participation will be impeded by the cultural traits of "traditional village societies" (p. 211).

So what is "culture" for the authors of this collection? Not surprisingly, different contributors use the notion in different ways. It ranges from a narrow focus on culture as expression (cultural sites or cultural practice) to culture as identity. In the Introduction, culture is portrayed as being broadly about "relationality" - the relations between individuals and groups. However, the book's overarching conception of culture is that it is something principally held by others. In the Introduction, and indeed the book as a whole, there is very little attention to the "culture" of the institutions, which are seen as undertaking public action; culture is apparently something possessed solely by the poor in the poorest countries. The exception to this is the chapter by Alkire Sabina, which sets out to answer the question of how agencies such as the World Bank should "address" culture, and notes that most analyses in the book fail to consider the culture of the World Bank itself. However, like the other chapters, this one does not go so far as to engage with the question of the international relations of inequality within which the World Bank is situated.

In the Introduction, the account of the literature on "culture in development thought" (pp. 9-18) presents two extremes. At one extreme are authors such as Lawrence Harrison and Samuel Huntington (2000), who are seen as hypermodernist and anticulture, and at the other extreme are those who can be said to be cultural critics of development (Escobar 1995 and Ferguson 1990). The editors of this collection claim to take a "moderate middle ground" (p. 11) between these two extremes. In so doing, however, they fail to consider contributions to the anthropology of development that have constructively engaged with the work of Escobar and others. Importantly, there is a sizeable literature that sees ethnographic accounts of the institutions of 
development and their location within broader global processes as key analytical areas (e.g., Grillo and Stirrat 1997; Mosse 2003).

The editors acknowledge that "some important topics at the intersection of culture and development" (p. 4) are not addressed in the book. These include globalization and the relationship between culture and economic growth, which "have been adequately treated elsewhere" (p. 4). But I would argue that this omission is an important failing of the book. Culture is seen as analytically problematic but "public action" is not.

\section{REFERENCE CITED}

\section{Escobar, Arturo}

1995 Encountering Development: The Making and Unmaking of the Third World. Princeton, NJ: Princeton University Press.

Ferguson, J. James

1990 The Anti-Politics Machine: Development, Depoliticisation and Bureaucratic Power in Lesotho. Cambridge: Cambridge University Press.

Grillo, Ralph, and Roderick Stirrat

1997 Discourses of Development: Anthropological Perspectives. London: Berg.

Harrison, Lawrence, and Samuel P. Huntington, eds.

2000 Culture Matters: How Values Shape Human Progress. New York: Basic Books.

Mosse, David

2003 The Making and Marketing of Participatory Development. In A Moral Critique of Development. Philip Quarles van Ufford and Ananta Kumar Giri, eds. Pp. 43-75. London: Routledge.

Kahnawa:ke: Factionalism, Traditionalism, and Nationalism in a Mohawk Community. Gerald F. Reid. Lincoln: University of Nebraska Press, 2004. 235 pp.

\section{NANCY BONVILLAIN}

Simon's Rock College of Bard

Gerald Reid's study of Kahnawa:ke, a Mohawk reserve located just south of Montreal, presents a persuasive analysis of social and political change during several important periods of the community's history. Although its goal is to focus on events occurring from 1870 to the 1940s, its lessons are applicable to contemporary processes as well.

Reid situates his argument in the context of anthropological analyses of Native American politics and the discourse of factionalism. His definition of factionalism-"a political process within a community that involves the interaction between informal political groups based on differential political interests" (p. xix)-is a critique of many previous interpretations of Native American community dynamics that view factionalism as a dysfunctional hindrance to social unity. In Reid's book, in contrast, factionalism is seen as an adaptive response to internal and external pressures, as groups of people with differing attitudes and interests compete with each other to promote their visions for the future of their communities. Factionalism, then, is an inherent part of processes of social and cultural change. Through the study of factionalism, Reid asserts the human agency in transformative events and directions for change.

Reid also stresses the role of factional disputes and interests in the development of traditionalism and nationalism in Iroquoian communities. Traditionalism is defined as processes that "revive and refashion indigenous political and cultural institutions and practices," whereas nationalism is a "movement involving organized efforts to identify with and develop ties to the Iroquois Confederacy" (p. xviii), especially as it struggles for political and cultural autonomy. Both traditionalism and nationalism were responses to Canadian colonial policies toward indigenous peoples. Reid traces the reactions of different groups to these policies, some worked within assimilationist models of adjustment while others opposed colonial control and developed indigenous systems of leadership and decision making.

One of the strengths of Reid's analysis is his reliance on multiple sources of information. He uses the extensive files of the Canadian Department of Indian Affairs containing reports of agents who molded and implemented policies and interacted with the Kahnawa:ke community. In addition to the official version of events, the files contain the voices of people from Kahnawa:ke in the form of letters and petitions as they reacted to government policies. Finally, Reid uses oral histories, collected from 1997 to 2002, from people who had personal or family knowledge of some of the pivotal events in the establishment of the longhouse on the reserve.

Reid focuses on three central periods relevant for contemporary politics and cultural movements at Kahnawa:ke. The first was the passage of the Indian Act in 1876 and its repercussions on the reserve. Factions immediately arose in response to the act, particularly its provisions mandating an elective system of government, overriding the traditional leadership by clan chiefs within the framework of the Iroquois Confederacy. Some groups opted to work within assimilationist models, although opposing the most overt forms of colonial control. Others adhered to traditional models of kin and community leadership. These issues continue to be relevant in controversies over representation, leadership, and decision making at Kahnawa:ke.

The second controversy revolved around the replacement of Native and lay teachers with nuns from the Sisters of St. Anne. Reid shows how the government transferred jurisdiction to the Sisters of St. Anne as one attempt to squelch Native identity and language on a reserve that actively opposed the Indian Act and its political and cultural ramifications. These issues find their contemporary reflection in community schools that emphasize teaching the Mohawk language and indigenous culture and history. Parenthetically, Reid's experience on the reserve began in 1980, when he was hired by the Kahnawa:ke Survival School to write social studies materials.

The third pivotal episode was the establishment of the traditionalist Longhouse in the 1920s, the local embodiment of the religious and revitalization teachings of the Seneca prophet, Handsome Lake. Reid shows that much of the membership in the Longhouse results from its cultural and political stance championing indigenous identity and autonomy, rather than just narrowly from its religious content. Longhouse members continue to be in the forefront of nationalist and traditionalist endeavors to strengthen 
alliances among the disparate Iroquoian communities in Canada and the United States as they struggle for political and cultural sovereignty.

Reid's study enlightens the discussion of current issues in Native communities through its meticulous use of historical data and contemporary testimony. And it successfully argues for the vitality of political discussion within these communities, not as a disruptive element but as part of the process of building consensus and achieving group goals.

Confronting the Occupation: Work, Education, and Political Activism of Palestinian Families in a Refugee Camp. Maya Rosenfeld. Stanford: Stanford University Press, 2004. 376 pp.

\section{AVRAM BORNSTEIN}

John Jay College, City University of New York

In what circumstances and to what degree can family organizations confront the inequalities in work, education, and political access suffered by Palestinians under the Israeli occupation? Furthermore, do the successes of Palestinian women in these struggles transform the power of patriarchy in their own lives? These are the main questions behind Maya Rosenfeld's study of Dheisheh Refugee Camp, south of Bethlehem in the West Bank and home to about eleven thousand people. Her general conclusions are that by working together, with some members sacrificing themselves so others can achieve, a cumulative process, usually occurring over generations, can improve a family's standard of living. Also, although some professional women enjoy relative autonomy on marriage, women's contributions to family struggle do not necessarily increase their independence from patriarchy.

Rosenfeld's book is divided into three sections, each focusing on an important aspect of life in the camp: wage labor, education, and political organization. In Part 1, she documents the work histories of numerous men and women, many of whom built and cleaned Israeli buildings for decades, the cramped housing in the camp, and the increased hardships caused by the closures of the 1990s. In Part 2, she documents the importance of UN schools in the camp and higher education outside the camp to achieve upward family mobility. She demonstrates a "chain-style process" in which a family sends one sibling to work so the next can study. The long-term cumulative consequences of employment and education benefit some families, but have had "uneven development" (p. 185) for women's independence from patriarchal control. In Part 3, she describes her hosts' experiences of lengthy imprisonment in Israeli jails and how this imprisonment heightened the politicization of individuals, families, and the community. She examines how the resources acquired over time by political labor are, and are not, commensurable with resources attained in employment and education.

Although Palestinian work, education, and political prisoners have been explored elsewhere, this is the most extensive recent ethnography in English on these topics, and it stands above others for its remarkable wealth of documentation. After occasional research visits to the camp during the first Intifada (1987-93), in 1993 Rosenfeld directed four assistants in an in-depth survey of 129 married couples. This was followed by a second study of every adult female in a single neighborhood of the camp, 446 women over 16 years of age. However, as she points out, the "sources that yielded information of utmost importance, in terms of both richness and depth, were the long-term, at times highly intense, relationships that [she] established with many dozens of individuals and with more than twenty families" (p. 20). Although she makes very insightful generalizations, the volume and quality of her material preserve the diversity of experience and emphasize the uniqueness of individual lives.

Rosenfeld's book is also noteworthy for something of which she writes little. She situates herself as an Israeli woman living in Jewish Jerusalem commuting to her Israelioccupied field site, and she discusses the politics of her identity in fieldwork. But given the importance of transgenerational processes in her analysis on Dheishians, it was a surprise to have relative silence on the importance of her own inheritance from parents. From the 1950s, her father Henry Rosenfeld, joined later by her mother Shulamit Carmi, wrote groundbreaking anthropological studies of Palestinian workers, class formation, and family organization. However, like younger Dheishians who "rarely acknowledged the influence of the generation that preceded their own (that of activists over age forty-five)" (p. 211), she names her parents in the dedication but buries reference to their work in the notes. To be fair, she might have avoided such references lest it appear immodest. But clearly, this book's sophistication shows an intellectual accumulation, allowing her to take activist and engaged social science to new heights.

This is an outstanding piece of research. Each section of the book-work, education, and political prisons-is substantial enough to be useful to the study of any one of these topics. Although it may be used as an introductory text, it is written for social scientists. It is strongly recommended for those studying Israel-Palestine, gender and patriarchy, or the struggle of dispossessed people, but it may also find a wide audience for those teaching ethnographic methods.

Governing China's Multiethnic Frontiers. Morris Rossabi, ed. Seattle: University of Washington Press, 2004. 296 pp.

\section{CHRISTIAN CULAS}

Institute of Research on South-East Asia (IRSEA-CNRS)

This book evolved from a three-day conference called "China's Management of its National Minorities," which convened in Washington, D.C., in February 2001. Several rounds of criticism and refinement went into creating the real intellectual homogeneity of this volume. In the Introduction, Morris Rossabi gives a luminous panorama of the main historical events in the relationships between Han and non-Han groups in China since the Han dynasty (206 B.C.E.-C.E. 220). Out of the seven chapters, two deal with 
minzu (ethnic group or nationality) in Xingjiang, two focus on Tibet, one concerns Inner Mongolia, another talks of the Yunnan province, and the last chapter discusses the Hui minzu, a Muslim group located in several areas of the People's Republic of China (PRC).

A number of important questions concerning interethnic relationships are at the heart of all the chapters; notably an analysis of how the Chinese Communist Party system uses the traditional hierarchical representation of the Han within the minzu to represent the ethnic minorities as "younger brothers in the great minzu family" (p. 27) or as "inseparable twins" (p. 146). More generally speaking, the book details a number of questions, such as the following: how do the Han propagandists use family ties (always clearly thought out in hierarchical terms) to express relations between two groups; how do ethnic populations deal with the authoritarian political system in PRC; how do they find a way for public expression of dissatisfaction while all media and meeting activities are strictly controlled; and how do some "Ethnic Autonomous Regions," such as Xingjiang, Inner Mongolia, and Tibet, continue to have full meaning when a large part of the population comprises recent Han migrants and most political officials at all levels are also Han? All of these questions are usually approached as local inquiries in a specific context. This method, however, ignores the fact that these issues stem from a top-down political system with a general view "to preserve the territorial integrity [and security] of the Chinese state" (p. 148). On another level, these questions have direct and deep political and anthropological implications not only in China but also in many countries dealing with ethnic groups (such as Burma, Laos, and Vietnam). This is especially the case when the local political culture does not accept negotiations and reciprocal compromises as a means of management between the people (ethnic or social groups) and the official organization. It would be very interesting to articulate studies on a local scale with a national focus in China, to establish links between these chapters, unveil a national logic, and illuminate the diversity of answers in the face of continual oppression of public means of expression. This kind of analytical scale variation, however, is not yet usual in collective publications.

The authors of this book are specialists in history, political science, anthropology, and religious studies. These multidisciplinary approaches, underlining the historical and political dimensions of interethnic relationships, bring a particular density and new articulations to the events described in this volume. The unity is best illustrated by the historical and political presentation in each chapter, giving a rich, diachronic, and articulate picture of the current situation in each region studied. The historical background of the editor Morris Rossabi also aids in this unity.

Rossabi suggests the studies of the relationships between southwestern Chinese minorities and foreign countries in Southeast Asia are "a potentially significant development that could serve as the subject for a separate book based on recent anthropological studies" (p. 11). There are indeed recent publications dealing with this subject, such as the following: Grant Evans, Christopher Hutton, and Khun Eng Kuah's Where China Meets Southeast Asia: Social and Cultural Change in the Border Regions (2000), and Jean Michaud's Turbulent Times and Enduring Peoples: Mountain Minorities in the South-East Asian Massif (2000). As many ethnic groups have settled in the mountainous regions of all the surrounding countries-China, Vietnam, Laos, Thailand, and Burma-it is easy to understand the interest in conducting comparative studies in border countries to highlight the historical, political, local, and cultural conditions producing current situations. Continuing further with Rossabi's idea, we hope that comparative studies of, among others, the Dai-Tai, Miao-Hmong, Hani-Akha, and the Yao-Mien in different countries can provide new and constructive orientations to the anthropology of change and to the dynamic of diversity inside the same cultural group.

\section{REFERENCE CITED}

Evans, Grant, Christopher Hutton, and Khun Eng Kuah

2000 Where China Meets Southeast Asia. Social and Cultural Change in the Border Regions. Singapore: Institute of Southeast Asian Studies.

Jean Michaud, Jean

2000 Turbulent Times and Enduring Peoples: Mountain Minorities in the South-East Asian Massif. Richmond, Surrey: Curzon Press.

Threatening Others: Nicaraguans and the Formation of National Identities in Costa Rica. Carlos Sandoval-García. Athens: Ohio University Press, 2004. 263 pp.

\section{TANYA BASOK}

University of Windsor

Theoretically sophisticated and analytically rigorous, Threatening Others provides a well-documented exploration of the processes that underlie the (re)production of national identities and their articulation with the "othering" of some groups of people. Focusing on the role of literary work, historical texts, and communications media (both printed and electronic) in shaping everyday lives, Carlos Sandoval-García combines textual and ethnographic analyses. The book traces the link between the formation of Costa Rican national identities and the racialization of the "other," such as indigenous peoples, peasants, blacks, and various working-class "foreigners." It focuses on the exclusion of Nicaraguan migrants in Costa Rica and how this relates to the representations of national identities. Having examined narratives on national identities expressed through newspaper articles, literature, and historical accounts, Sandoval-García contends that, both historically and today, Nicaraguan migrants or "Nicas," as they are called in Costa Rica, have been portrayed as uncivilized, uneducated, and unhealthy people who "invade" Costa Rica, drain the country's social security system, and engage in criminal activities or social protest on its territory. By contrast, Costa Ricans are represented as people 
deeply committed to democracy, peace, law and order, and public consensus. The differences between the Costa Ricans and Nicaraguans are related to the racial uniqueness of Costa Rica as a "white" nation within Central America.

Sandoval-García pursues three goals in this book. First, he documents how Costa Rican national identity is constructed by means of exclusion and the projection of undesired images onto the Nicaraguan (and other) "outsiders." Second, he examines how the hegemonic representations of the Costa Rican nation and the undesirable other are decoded and contested in everyday life. And third, he relates specific configurations of national identities to their spatial and temporal locations, and explores the multiple and diverse links within and between representations situated in different temporal and spatial locations.

Sandoval-García discusses how hegemonic historical texts portray Costa Rica in the 18th century as a "rural democracy" with the peasant being the crucial figure in the country's political, social, and cultural life. He also explores how this representation has become a symbol of Costa Rican nationhood. In the 19th century, the idyllic depiction of Costa Rica as akin to Europe in its pursuit of progress and modernity is contrasted with the rest of Central Americaand particularly with Nicaragua.

At the same time, Sandoval-García illustrates how this idyllic image of Costa Rica as a rural democracy is questioned in several novels and through historical research, which has revealed social differentiation and inequalities in the early history of this country. In addition, this image is undermined by an emergent middle-class imagery, accompanied by the stigmatization of peasants as simpleminded and uncivilized folks in literary works and through other discourses. Although the representation of Costa Rica as a rural democracy may have been transformed, the image of Costa Rica as a predominantly white nation strongly committed to modernization, peace, and order has endured over time. Just as durable have been the portrayals of darkerskinned, working-class "Nicas" as trouble makers, criminals, bearers of epidemic diseases, and burdens on the Costa Rican social welfare system.

Sandoval-García does not wish to limit his research to an analysis of printed narratives. He is similarly interested in the readership of official discourses. To explore how hegemonic representations of Costa Rica and Nicaraguan migrants are appropriated or contested in everyday life, Sandoval-García conducts fieldwork research among Costa Rican primary and secondary school students, Nicaraguan immigrants, and nongovernmental organizations (NGOs). Not surprisingly, he finds that images of Costa Rica and the representation of Nicaraguan migrants by students are mediated by the students' age, school location, and income class. Although many students idealize Costa Rica as an "ecodemocracy" and express pejorative views of Nicaraguans, some students believe that human rights principles apply similarly to Nicaraguans living in Costa Rica and nationals. At the same time, Sandoval-García reports that several NGOs have voiced their concerns about the exploitation and abuse of Nicaraguan migrants and have organized to defend their rights. And finally, Sandoval-García discusses Nicaraguan networks of solidarity as a form of contestation to the stigmatization.

Sandoval-García deconstructs hegemonic discourses on Nicaraguans as a threat to Costa Rican racial purity or its welfare state, and redirects the explanations of deteriorating standards of living in Costa Rica to an analysis of the threats posed by neoliberal policies to Costa Rican social safety and public security. He also calls for the decentering of national identities in public discourses in order to promote more tolerance and respect for cultural diversity.

In sum, Threatening Others is a commendable book of great interest to students of ethnic and national identities, cultural theory, and Latin American studies.

Violence in War and Peace: An Anthology. Nancy Scheper-Hughes and Philippe Bourgois, eds. Malden, MA: Blackwell Publishers. 2004. 496 pp.

\section{ANDREW STRATHERN}

University of Pittsburgh

\section{PAMELA J. STEWART}

University of Pittsburgh

The editors of this volume aptly call it "this expansive, eclectic, anthropologically informed anthology" (p. 2). They also note the protean character of its topic, recognizing that "violence ... defies easy categorization" (p. 2.). They reject any idea that, for example, "killing can be explained by or linked to a specific set of biopsychological universals," arguing that human action is always culturally mediated (pp. 14-15). They employ instead their concept of "the continuum of violence," which implies continuities between small-scale or everyday actions and large-scale or dramatic ones such as genocide. Their volume, therefore, "strives, above all, to 'trouble' the distinctions between public and private, visible and invisible, legitimate and illegitimate forms of violence in times that can best be described as neither war nor peacetime in so many parts of the world" (p. 4). The readings here deliberately juxtapose different contexts of violent actions so as to represent this approach (p. 5). The result is a rich, poignant, disturbing, and at times confusing set of observations on contexts of violence around the world today: easy to look into and follow certain themes, perhaps more difficult to use if one were an instructor who tried to go through and refer to all or most of the collection in a specific class.

The different parts of the volume are (1) Conquest and Colonialism; (2) The Holocaust; (3) The Politics of Communal Violence; (4) Why Do People Kill?; (5) The State Amok: State Violence and Dirty Wars; (6) Violence and Political Resistance; (7) Peacetime Crimes: Everyday Violence; (8) Gendered Violence; (9) Torture; (10) Witnessing/Writing Violence; and (11) Aftermaths. 
Scheper-Hughes contributes six chapters, and Bourgois three. There are 62 chapters in all, with a panoply of reprinted contributions by, for example, anthropologistssociologists: Michael Taussig, R. Brian Ferguson, Robert Gordon, Liisa Malkki, Renato Rosaldo, Allen Feldman, Begoña Aretxaga, Veena Das, Pierre Bourdieu, and Paul Farmer. There are pieces from Joseph Conrad, Michel Foucault, Primo Levi, Hannah Arendt, Stanley Milgram, Elaine Scarry, Noam Chomsky, Jean-Paul Sartre, George Orwell, Frantz Fanon, Giorgio Agamben, and Wole Soyinka among many others.

Inevitably, with such a large selection, we receive as readers only a brief and truncated version of the thinking of a particular author. Michael Taussig's well-known piece from his 1987 book, Shamanism, Colonialism, and the Wild Man (Ch. 2) comes through effectively; the excerpt from his 1992 book, The Nervous System, on "terror as usual" (Ch. 31) seems too short and elliptical. The abridged summary of Brian Ferguson's exposition in the journal "Scientific American" on "tribal warfare" (Ch. 5) can in no way stand as a full accounting for that category of planned, hostile action or as a full representation of the argument developed in War in the Tribal Zone (Ferguson and Whitehead 1992). The abridgement of Joseba Zulaika's work (Ch. 54) plunges the reader into Basque politics and violence, but why is it titled "The Anthropologist as Terrorist"? The effect is more of a sound-bite than a chapter. Yet, even with brevity, many of these excerpts do come over powerfully and well, such as Begoña Aretxaga's (Ch. 29) on ethnic violence and gender in Northern Ireland or Veena Das's (Ch. 40) on language, body, and transactions in pain in India. Creative instructors must find their way through these thickets of analysis, description, and activist witnessing, following the particular theoretical leads that they choose to employ. There is no shortage of choice here: The book is like a large supermarket of representative case materials, or perhaps like a ride to Widdicombe Fair, with everyone seated on the horse of the continuum of violence.

We have two specific comments: We appreciated the editors' sensible remarks about Yanomami warfare and Patrick Tierney's allegations (p. 15, introduction by ScheperHughes and Bourgois), but it should be Timothy Asch here not "Ash." We also were glad to read Zulaika's observation that "the accusation of terrorism, like that of witchcraft and demonic possession in former times, allows us to deface the accused person and thereby deprive his or her most intimate humanity" (p. 419). This echoes the much earlier observations by Edmund Leach in his 1977 discussion of "Custom, Law, and Terrorist Violence" on this matter. It is also akin to an argument we have been developing for some time, for example in our Witchcraft, Sorcery, Rumors, and Gossip book (Stewart and Strathern 2004) and our volume coedited with Neil Whitehead on Terror and Violence: The Imagination and the Unimaginable (in press). We stress, further, as many others have done, that witchcraft and sorcery are contemporary phenomena in many parts of the world, not safely confined to "former times."

\section{REFERENCE CITED}

Ferguson, R. Brian

1992 Tribal Warfare. Scientific American 266(1):108-113.

Ferguson, Brian, and Neil Whitehead, eds.

1992 War in the Tribal Zone. Santa Fe: School of American Research Press.

Stewart, Pamela J., and Andrew Strathern

2004 Witchcraft, Sorcery, Rumors, and Gossip. Cambridge: Cambridge University Press.

Strathern, Andrew, Pamela J. Stewart, and Neil L. Whitehead, eds.

In press Terror and Violence: The Imagination and the Unimaginable. London: Pluto Press.

Taussig, Michael

1987 Shamanism, Colonialism, and the Wild Man. Chicago: University of Chicago Press.

1992 The Nervous System. New York: Routledge.

Andean Archaeology. Helaine Silverman, ed. Malden, MA: Blackwell Publishing, 2004. 342 pp.

\section{RICHARD L. BURGER}

Yale University

It has been nearly two decades since the publication of the last reader in Andean archaeology, and those who teach this subject in universities will welcome the news that an up-to-date replacement for Richard Keatinge's Peruvian Prehistory (1988) has finally appeared. Containing 13 chapters commissioned especially for this volume, the book is explicitly designed as a companion volume for Michael Moseley's popular introductory textbook, The Incas and Their Ancestors. Edited by Helaine Silverman, one of the field's broadest and most prolific scholars, and containing contributions by many of the field's most active senior and junior investigators, there would seem to be little to do other than celebrate. Unfortunately, the creation of an outstanding undergraduate reader requires more than bringing the right authors together. It requires that the articles be visually attractive and intellectually engaging while also being accessible to undergraduates. Although some chapters in this volume rise to this level, many do not.

The volume's problems begin with the editor's introductory chapter, which focuses on problematizing the chronological framework and the exploration of theoretical notions of cultural landscape. The discussion on chronology will mystify most undergraduates, particularly given that the following chapters all use the conventional chronological scheme mechanically and without comment. Silverman's discussion of cultural landscape is an interesting but stylistically dense contemplation that does little to set the stage for the following chapters for the intended audience. Despite the editor's caveats, volumes of this kind are always faced with issues of coverage, because potential consumers of a reader expect it to cover roughly the same subject matter as the textbook, albeit with deepened insight and greater detail.

The editor attempted to deal with the challenge of parallel coverage by arranging for chapters to be cowritten by multiple authors with differing area specialties. This "shotgun wedding" approach produced uneven results. In some cases, such as the chapter on the Late Intermediate Period, 
it is a real success. In several other chapters, such as the one on the Preceramic, the results seem as if a committee had written them; what these chapters gain in expertise they lose in coherence and a distinctive voice or perspective. Despite the editor's best efforts, the coverage remains uneven, with the five-century Middle Horizon being the focus of three-and-a-half chapters while the 2,000-year "Formative" is discussed in little more than a single chapter. The limitations in content are reinforced by the paucity of illustrations, averaging less than two figures per chapter. Even in those cases in which line drawings or photographs are included, the quality of the printing (e.g., fig. 8.3) or the size of the reproduction (e.g., fig. $9.1 \mathrm{c}$ and d) make them almost useless.

Despite the book's weaknesses, there are many strong chapters that may lead some to adopt it for teaching. The second half of the reader is particularly strong, and this is welcome for those using the Moseley (or Richardson) textbooks. The discussions of Huari and Tiahuanaco are particularly interesting, and Janusek's treatment of Tiahuanaco urbanism should not be missed. Ran Boynter's general synthesis on Andean textiles is refreshingly lucid and the chapter by Lisa DeLeonardis and George F. Lau on the Early Intermediate cultures of the South Coast and northern highlands offers a nice contrast to the textbook treatments. Two other chapters on Chavin de Huantar by Sylvia Rodriguez Kembel and John W. Rick and on the emergence of the Incas by Juha Hiltunen and Gordon F. McEwan are more radical and offer interpretations sharply different than those found in the Moseley volume. Some scholars, including this reviewer, may find these contributions to be deeply flawed. In any case, instructors will need to program extra class time to analyze the assumptions, methodology, and evidence underlying these chapters, if they are to use them in undergraduate teaching.

In the end, the editor must be congratulated for an ambitious effort. No specialist in Andean archaeology will want to miss this volume. But it is too soon to know whether, as was the case with the Keatinge volume, the book's strengths are ultimately judged to outweigh its weaknesses in a classroom setting.

\section{REFERENCE CITED}

Keatinge, Richard W., ed.

1988 Peruvian Prehistory: An Overview of Pre-Inca and Inca Society. Cambridge: Cambridge University Press.

The Political Landscape: Constellations of Authority in Early Complex Polities. Adam T. Smith. Berkeley: University of California Press, 2003. 346 pp.

JOHN M. STEINBERG

University of California, Los Angeles

In his new book, The Political Landscape, Adam T. Smith describes how space and physical objects are used to create and enhance political authority. Smith specifically looks at the role that the imagined city or the imagined landscape plays in forging the experience of an actual city or an actual landscape. Smith asks where the elites were sited and how their use of physical form contributed to the creation and reproduction of constellations of political authority. The answer, according to Smith, is not at all universal because the use of the landscape and built environment varies from place to place. The one constant is that place is always important and always idiosyncratic. To demonstrate differences in the use of landscape and the built environment, Smith employs three case studies: Central America, Caucasia, and Mesopotamia.

Smith argues that the landscape, the city, or the temple plays a critical role in creating and maintaining political authority. Hence, the results of settlement pattern studies, and other tools of regional analysis (e.g., nearest neighbor, central place, and rank size), are misleading because they assume a universality of landscape that reflects social organization. Smith believes that much of past anthropological archaeology has been directed to find "temprocentric" regularities at the expense of the examination of specific landscapes and built environments and has therefore missed the built environment's active role in creating political authority.

Consequently, if one is dissatisfied with basic theories of human social evolution that operate through time and across space (e.g., those put forward by Marshal Sahlins, Marvin Harris, Michael Mann, Elman Service, Allen Johnson, and Timothy Earle), then Smith's approach is a welcome addition. Smith posits that archaeological investigations based on "mechanical evolutionism" have simply reified a set of types and models (e.g., tribes bands, chiefdoms, and states). He argues that theories of state-level social inequality that employ coercion, social contracts, costs, and benefits are simply inadequate. He charges that states are "illusionary," which is an apparent attack on the concept of the state that echoes Norman Yoffee's questioning of the concept of chiefdom. According to Smith, arguments that employ textbook social evolution are "undertheorized," "teleological," and "tautological."

The intended audience of this book is unclear, but it is probably not students of archaeology. A myriad of philosophical terms (well beyond tautological and teleological) are bandied about with hardly a definition. Conversely, basic archaeological features (e.g., the Middle Eastern tell) that would be covered in any introductory archaeological text are defined in great detail. Whoever the readers may be, they will need substantial dedication, for the writing is dense.

A few sections and chapters are outstanding. For example, in Chapter 2, the section on the intellectual history of the term state is thought provoking, as is the section on authority. In Chapter 4, Smith's discussion of his own work in Caucasia is excellent and relevant to his ideas on the importance of location. The change in voice, that he himself notes, is quite refreshing: Absent are the long, tangled sentences, the harsh criticisms of past research, 
and the philosophical jargon that fill the rest of the book. Smith effectively describes how elites in Caucasia took extraordinary measures to create space and environments that would both produce and legitimize their authority. He makes it clear that the elites' use of space was specific to that environment. As a result, his idea of the idiosyncratic role of the landscape in the creation of political authority flows easily and convincingly from his Caucasia data.

However, the extension of the specific role of the landscape to other areas and civilizations is not convincing. Chapter 3, a discussion of the Classic and Post-Classic Maya, is a strained attempt to refute the usefulness of regional analysis. Chapter 5, on Mesopotamia, centers on the differences between a textual impression of coherent city space and the archaeological reality of highly fragmented walkways, streets, and neighborhoods. This difference, according to Smith, reflects an elite strategy to create an "imagined" city that contributes to the creation and reproduction of political authority.

In Chapter 6, Smith redefines the term institutions. Institutions, as a socioeconomic focus of study, arise from Thorstein Veblen's work and have been productively used by the likes of Mary Douglas and Douglass North. The term traditionally refers to settled habits of thought common to groups of people (i.e., the rules of the game such as property rights). Smith's new definition attempts to tie institutions to the built environment. His analysis of Urartian temples and fortresses using his measure of real relative asymmetry is creative (although I am not sure how robust it is), but the measure does not seem to relate in any obvious way to the nature of institutions, either as commonly used in anthropology (e.g., James Acheson's work) or in Smith's redefined form.

In the end, Smith's postmodern approach to the landscape implies that basic tools of regional analysis-which rely on organic development of population clusters responding to economic or market forces-are unreliable tools for research. For Smith, the built environment is not a reflection of the socioeconomic structure but, rather, a cause of that structure. This approach is certainly well theorized and not at all teleological, but I am skeptical as to how helpful it will turn out to be.

Musqueam Reference Grammar. Wayne Suttles. Vancouver: University of British Columbia Press, 2004. 632 pp.

\section{BRIAN THOM}

McGill University

Musqueam Reference Grammar is a monumental work by the celebrated scholar of Northwest Coast cultures, Wayne Suttles. It is based on over 50 years of research in Coast Salish communities in British Columbia, Canada. The book provides a detailed description of the grammar of the Musqueam dialect of Halkomelem, one of the major Salishan languages spoken on the Pacific Northwest Coast.
Suttles's lifelong anthropological experience and close relationship with the Musqueam people are brought to bear on his work, providing significant depth of cultural context in describing this Salishan language and its use in local discursive contexts.

As a work of descriptive linguistics, Suttles's Musqueam Reference Grammar is a rich analysis of the structure and functioning of a language with numerous distinctive features. The structure of the book follows a typical grammar with sections on phonology, morphology, and syntax, with the addition of useful chapters on kinship, space and time, place names, and personal names. Importantly, Suttles has demonstrated methodological rigor by having generated the grammar largely from forms observed in recorded, spontaneous texts, clarifying mechanics of grammatical form and structure by elicited responses from elders who speak fluently. The examples that demonstrate the grammatical forms being discussed show a consistent attention to providing not only clear examples but also culturally and semantically rich selections of language usage. These examples are supplemented throughout with excellent footnotes that provide comparative contexts and analyses of issues from relevant linguistic, ethnographic, and historic literature. Taken as a whole, the reference grammar provides a consistently interesting sense of the cultural concerns expressed in Musqueam discourses.

A descriptive grammar such as this is useful not only as a linguistic reference work, but in developing anthropological perspectives that seriously consider how the interplay of language and culture become an important and dynamic factor in how local cultural lives are experienced and communicated. Suttles's Musqueam Reference Grammar gives numerous examples that illustrate, from different levels of the grammar, the fundamental links between language and culture, including a detailing of how kin terms reflect and reinforce social structures, and a chapter on the ways metaphors of embodiment and dwelling are eluded to in directional and spatial terms. These and other examples taken from the Musqueam dialect of Halkomelem provides an important source of information for comparative linguistic research and an invaluable reference for scholars working in Salishan-speaking or other Northwest Coast communities.

Suttles writes with an authoritative cautiousness, plainly stating what he is certain of and spelling out the limits of his data and his grammatical analysis and assumptions. The book is written with a refreshing humility and respect for the limitations of this kind of inquiry as well as the complexities of practiced language and culture. This work is not, nor does it claim to be, a study to address questions of theoretical linguistics. Suttles has instead turned his attention to providing a thorough discussion of a language with, at best, only a few hundred fluent speakers. Both the local and the scholarly communities are well served by this decision, as the Musqueam Reference Grammar will very likely remain the central descriptive work on a Salishan language for generations to come. 
Consuming Motherhood. Janelle S. Taylor, Linda L. Layne, and Danielle F. Wozniak, eds. East Brunswick, NJ: Rutgers University Press, 2004. 323 pp.

\section{LYNN HORRIDGE}

The Graduate Center, City University of New York

Contributors to this provocative anthology view motherhood through the lens of consumption and show the utility of the approach ethnographically. Scholars of motherhood and reproduction have now moved beyond the usual anthropological treatment of kinship as social relations based on persons to explore kinship as social relations based on things. Of particular interest is a focus on European and North American mothers as consumers of and participants in services related to motherhood, such as adoption, foster care, obstetrics, and midwifery.

The anthology begins with two framing chapters, or "Con-Texts," by Barbara Katz Rothman and Daniel Miller (reprinted from 1989 and 1997, respectively). Rothman emphasizes motherhood and questions the moral implications of the language of property in the context of mother-child relations. She points to the disconnect between the right to own a child and the responsibilities of raising a child in patriarchal societies. In contrast, Miller emphasizes consumption. He experiments with psychoanalytic theory to propose that middle-class mothers have generated a new "cult of the infant." Miller suggests that mothers' practices in shopping for infants may replace religion as a form of individual transcendence for women struggling to manage identities at the crossroads of younger feminist ideals and aging desires to mother. Miller's chapter serves as the reference point of the volume to which the remaining authors respond-often in antagonistic yet theoretically compelling ways.

For example, Ann Anagnost expands on her work on the adoption of female infants from China by exploring U.S. adoptive parents' role in the creation of a "sentimental economy" in response to late-20th-century consumer capitalism. In an attempt to archive children's identities, many adoptive mothers combine handcrafted and purchased objects to create "memory books" - a sincere task that Anagnost may see as falling short of creating a meaningful connection between sites of production and consumption in transnational adoption exchange.

Consuming Motherhood may provoke caution among scholars long concerned with mother as producer, now asked to reconsider mother as consumer. In line with Igor Kopytoff's closing commentary on the ubiquity of economism in kinship relations, it is the perception of commodification in relation to persons that varies across cultures. In the West, the explicit commodification of persons may puncture our sacrilized notions of human relations, especially in light of slavery and historical guilt. In her Introduction, editor Janelle S. Taylor addresses this perception. Following a discussion of Marx's definition of a commodity and the nature of wants that may spring from stomach or fancy, Taylor asks: "How can the bearing of children be likened to the ingestion of food? The very suggestion seems to invoke that most frightening of all monsters, the mother who eats her own children" (p. 11).

If Jonathan Swift's modest proposal to cure the social ills of Ireland has not yet come to mind, Gail Landsman successfully weaves it into her chapter on mothers of children with disabilities, in which she argues that disabled children are classified as commodities, particularly as damaged goods. In discussing Peter Singer's notorious claim about the loss of full personhood by way of physical disability, Landsman reveals these mothers' constant struggle with an assumed societal perception that if they could exchange their children for "healthier" ones, they would. Showcasing these mothers' participation in the disability rights movement, Landsman frames their consumption practices as coping strategies in an effort to have children "fit in" to the very consumer culture to which they are opposed.

Is consumption a useful approach to motherhood? In her instructive closing commentary, Barbara Katz Rothman comments that it is "terrifying to see all this put together this way" (p. 270). However, as both her chapters show, the uncomfortable connotations inherent to this approach merely reflect the ways in which today's capitalism forces persons to relate. The compulsion of the remaining contributors to do battle with Miller's seemingly superficial treatment of mothers as shoppers does produce exciting results. In light of the exhaustive span of inquiry this battlefront inspires, one walks away satisfied that the authors have done justice to the issues at hand, not the least of which is the supposed inability of scholars to critically examine reproduction and consumption as mutual reinforcing phenomena. This text provides engaging reading for students of medical anthropology, kinship, consumption, and materialism as well as for feminists concerned with reproduction, social movements, and the professionalization of "women's work."

Biological Anthropology and Ethics: From Repatriation to Genetic Identity. Trudy R. Turner, ed. Albany: State University of New York Press, 2004. 327 pp.

\section{ROBERTO DELGADO}

Hunter College, City University of New York

The issue of ethics in anthropological study has evolved with the discipline. Traditionally, the concerns focused on respect for those peoples and cultures that were the subjects of research. More recently, ethical concerns have begun reaching into many aspects of academia and scientific investigation, and each of the subfields of anthropology now recognizes its own unique concerns, from issues regarding the treatment of archaeological artifacts and sites, to matters of obligations between field researchers and both the human and nonhuman primates they study. The subfield of biological anthropology is perhaps among those subject to the most scrutiny by society and governing bodies because 
of its multifaceted approach of studying the biological basis of human behavior, diversity, and evolution. For example, there are potential biomedical and sociopolitical implications in establishing and emphasizing close evolutionary relationships between prosimians, monkeys, apes, and humans, and describing genetic differences among modern human populations. In addition, biological anthropologists face a bewildering array of ethical dilemmas such as how to interact with and collect data from human adult and child subjects from other cultures, rendering a decision on the disposition of recent and fossil skeletal remains, including questions of accessibility and repatriation, and issues related to the humane treatment of study subjects in captive settings and the conservation implications of conducting research on nonhuman primates in the wild.

Trudy's Biological Anthropology and Ethics is the first volume that addresses a selection of ethical issues encountered by professionals and students trained in biological anthropology, with specific case studies and commentaries under each of the five major subfields of the discipline: genetics, human biology, paleontology, primatology, and skeletal biology. The first section of the volume offers contributions on field and laboratory research on nonhuman primates and collectively emphasizes the many challenges faced by primatologists both in captive settings and in the field. These challenges may range from acquiring access to and transporting biological samples to dealing with misconceptions by local communities in host countries and needing to learn acceptable rules of conduct that should not harm study subjects and promote future research in the region. In the field, the quick and unpredictable turnaround of events in politically unstable nations also poses problems that raise another series of ethical issues with which to contend. Not the least of which deals with prioritizing self-preservation at the cost of sacrificing funds and equipment bequeathed by generous sponsoring agencies, and reneging on commitments to local community members who were promised positions as camp staff, guides, and research assistants.

Another important ethical consideration deals with the impact that researchers might have on their study subjects, and this matter is particularly precarious when field studies necessitate the habituation of endangered species. Endangered nonhuman primate species already face multiple threats exacerbated by human population growth that include habitat loss, hunting, and live capture for biomedical research, entertainment, and the trade in exotic pets. Habituation of free-ranging primate groups has lasting consequences that affect patterns of behavioral ecology, the health and well-being of research subjects, and the vulnerability of study populations to disease and hunting. Only through long-term commitments that include promoting protected areas and establishing the infrastructure and training necessary to withstand episodes of civil or political unrest can researchers be assured of helping to preserve valuable populations for future study.

The general theme coursing through the other sections of this text, dealing principally with human biology, genet- ics, and the skeletal remains of living and fossil humans, is that of opposing but legitimate claims presented by competing groups. These groups include the scientific community and parties who claim either an ancestral-descendant relationship or a cultural affiliation with the remains in question. The applied work of forensic specialists contributes still another level of complexity to the discussion of ethical issues in biological anthropology because of their ties to the legal establishment and frequent involvement in criminal investigations. Clearly, practitioners in each subfield of biological anthropology face unique ethical challenges and must strive to behave responsibly in their activities.

Overall, the summary chapters are the most insightful in terms of describing the major ethical questions in each of the subfields of biological anthropology. The contributions presenting specific case studies are excellent for exploring a particular issue in more detail including, in most cases, a strong recommendation for addressing conflicting interests. Overall, this edited volume galvanizes discussion in this important matter of ethics in biological anthropology and promotes institutionalized cooperation with an equitable exchange of resources between the research community and larger society. This book will serve to spur further deliberation.

The Intimate Economies of Bangkok: Tomboys, Tycoons, and Avon Ladies in the Global City. Ara Wilson. Berkeley: University of California Press, 2004. 272 pp.

\section{LOUISA SCHEIN}

Rutgers University

In this variegated ethnography, Ara Wilson has deftly reinvigorated the best of the tradition of anthropological holism. Intimate Economies takes as its chief goal to demonstrate, through case examples, the complexity of articulations that constitute the Thai economy. Not only does she provide a sustained treatment of the interaction between globalization and what she calls the "folk," "kin," and "moral" economies of longer standing in Thailand, but she also reveals, through intimate research, the ways in which other domains of life-especially gender, sexuality, and family-both impact and are impacted by economic change. Her clearly argued dialectical model both insists that "the increasingly global market economy integrates and remakes social worlds" (p. 189) and also "moves from an image of an external penetrating force to a view of transformations unfolding within Thai society" (p. 194).

Wilson is innovative in her research design, siting her investigation across several social domains in Bangkok. She calls this a "multi-sited" method, but in many ways the best of her data come not from the choice of multiple institutional locations-whether department stores, go-go bars, or telecommunications companies-but from the vivid account of socioeconomic actors that she presents as engaging the shifts in the Thai economy. In five substantive chapters, we meet multiple types of agents who are fashioning 
themselves and their social worlds through their economic practice: a business tycoon who founded the first department store in Thailand (creatively researched through commemorative funeral texts); sex workers; mall shoppers, especially the somewhat masculine-gendered "tom;" a creator of an influential cable TV company and his cosmopolitanizing employees; and revamped entrepreneurial subjects of direct sales marketing. Without navel gazing, Wilson skillfully recounts her own engagements with these subjects, pioneering a multifaceted research approach that included working at the telecommunications company, hanging out in malls, and going to training sessions for Avon and Amway. We see her participating, observing, and conversing with her interlocutors throughout a narrative that is always attentive first to them and their socioeconomic milieux. She opts for an athletic text, refreshing in its leanness (195 pages), foregoing additional thick descriptions, which might have also been fascinating.

One of Wilson's key themes is the gendering of economy. She opens with a treatment of the noted tourist attraction, the Bangkok floating market, which poses a contradiction because, despite being a place where women predominate, prevailing discourses about the Thai economy make this type of folk domain invisible, instead gendering the economy male. Wilson goes further in exploring the interface between economy and gender-sexuality in her treatment of the toms' use of shopping malls. The tom, she explains, is an artifact of modernity, and their performance of masculine attributes_-short hair, male clothing, cigarette smoking, having a feminine "dee" on their armis closely imbricated with consumption practices associated with new forms of leisure. Toms not only work in malls, but they also use that space for socializing, because they do not have the kind of dedicated spaces-bars, saunas, or particular lanes-in which gay men and "kathoey" spend their leisure time. What is fascinating about the mall space, however, is, as Wilson shows, that it reveals itself to be a site for the purveying of "commercial heterosexuality" dominant images in promotional culture that enshrine the young romantic male-female couple or the reproductive family as target consumers. Because "consumers realize various identities through commercial venues," Wilson finds that these images of heterosexuality are no deterrent to tom self-fashioning through mall consumption: "It is the version of romance, not the same-sex character, that is 'imported' in the tom and dee phenomenon" (p. 127). In other words, the homosocial relations of tom and dee appropriate valorized images of romance to craft their own intimacies.

It is this type of sophisticated argument, combining the insights of anthropology, cultural studies, and area studies, that makes Intimate Economies so rich. Wilson employs contemporary theory, but displays it mostly in endnotes of stunning bibliographical thoroughness to insure readability of the text. One never questions that Wilson-who identifies herself with the tradition of economic anthropology in her integrative attention to production, distribution, and consumption-is also in full command of interdisciplinary theories on the global economy (although her capable treatment of flexible citizenship and entrepreneurship might have been enriched with deployment of enabling notions such as neoliberalism and governmentality). Yet her project is never reducible to the global, as she insists throughout that what is important about the economic is that it is plural and immanent in the most intimate aspects of subjectivity and practice.

Culture and the Question of Rights: Forests, Coasts, and Seas in Southeast Asia. Charles Zerner, ed. Durham, NC: Duke University Press, 2003. 289 pp.

\section{CELIA LOWE}

University of Washington

Culture and the Question of Rights is a delightful volume formulated at the intersection of the poetics and politics of nature in the Malay world. The chapters provide phenomenological evocations of the following: place (the Malaysian rainforest, spirit-inhabited promontories of the Makassar Strait, and the Kalimantan swiddens of Bentian, Salako, and Meratus Dayaks); species (fruit trees that tell the story of kinship, bees that cross the River of Changes to provide honey, and marauding elephants that bestow dream song genres); and histories (the Bagak past told through durian plantings, Mandar "heirloom" templates for contact with ancestral spirits, the arrival of British colonial cartographers, and the contemporary Malay state into the Temiar homelands). Poetic descriptions of place, species, and histories are intertwined with stories of property rights and ethnic and resource politics: court settlements governing flying fish roe collection off the Mandar coast; documents written by Bentian Dayak leaders protesting the arrival of Georgia Pacific and other logging corporations; and the forced removal of Hakka Chinese from their cultivated rice fields in lowland Kalimantan during Indonesia's anti-Communist purges in the 1960s. The book's artful synthesis of poetics with politics makes its intervention theoretically astute, ethnographically informative on contemporary resource struggles in Southeast Asia, and a pleasure to read.

Any emphasis on poetics is essentially an emphasis on form. Each of the chapters in Culture and the Question of Rights attempts to recuperate, as rational and logical, Malay peoples' ways of knowing land- and marinescapes, and their expressive forms for communicating about the social and natural world around them. As Anna Tsing writes, "Meratus Dayaks know a great deal more about the technical features of their forests than any of the 'experts' I met in the region" (p. 33). In chapters by Tsing, Marina Roseman, and Nancy Peluso, Meratus, Temiar, and Bagak ways of comprehending the natural world around them imply the permeability of human and nonhuman worlds in contradistinction to the Enlightenment separation of nature and culture.

Although each author attempts to reclaim reason for the people about whom she or he writes, these chapters also 
describe negotiated translations across instrumental reason and practical knowledge, and indigenous notions vie for authority with more familiar bureaucratic forms of science, law, and governmentality. For example, Charles Zerner describes the decision of the Majene District Court that the sea is "public," thereby invalidating Mandar conventions of marine tenure. Likewise, Stephanie Fried describes how Bentian Dayak leaders "write for their lives" to narrate Dayak swidden agriculture in the forms of nation, science, and bureaucracy recognizable to national authorities.

At the same time, bureaucratic and scientific forms of instrumental reason are also revealed as contingent and reliant on their own poiesis. For example, Fried cites a Dayak farmer who argues the Indonesian state has "become a victim of advertising" (p. 167) in viewing swidden agriculture as the enemy of development. Similarly, Peluso, Zerner, and Fried all observe that national elites are the beneficiaries of land redistribution, new marine property arrangements, and resource monopolies underwritten by narratives of instrumental reason.

Although each chapter presents alternative logics of nature and community, the authors wisely avoid any claims on behalf of "primitive conservationists." Tsing writes Meratus Dayaks are not "animal lovers"-like all other people, they know nature through culture. Roseman, likewise, writes that, under conditions of social dislocation, Temiar people guide loggers into their dream-song forests and hunting preserves. "Eco-philosophy" is always historically contingent in these chapters.

Two concluding chapters, one by Donald Brenneis and one by Jane Atkinson, tie the volume together. Brenneis asks, given different epistemological worldviews on nature, culture, property, and history, how best can Southeast Asia's marginalized peoples claim legitimacy? He asks us to consider both renewing appreciation for local specificity and challenging the terms of modernist frameworks as valuable starting points. From a different angle, Atkinson asks "will exposure to multiple lines of vision grant clarity or confusion to the picture" (p. 246)? She seems less convinced than other authors here of the power of new narratives to contest the boundaries of reason.

The eight chapters in this volume open up a space for contemplating the common fate of people and nature in the modern world. Culture and the Question of Rights will be theoretically engaging to critical scholars of nature and culture hybridity, and it will capture the attention of undergraduates exploring Southeast Asian environments for the first time. 